\title{
La sostenibilidad del Tercer Sector de la Comunicación en España. Diseño y aplicación de un modelo de análisis al estudio de caso de El Salto y OMC Radio $^{1}$
}

\author{
Alejandro Barranquero ${ }^{2}$ y José Candón-Mena ${ }^{3}$
}

Recibido: 17 de enero de 2020 / Aceptado: 12 de agosto de 2020 / Publicado: 12 de enero de 2021

Resumen. El Tercer Sector de la Comunicación se compone de medios y proyectos de comunicación alternativos gestionados por entidades no lucrativas (asociaciones, cooperativas, ONG, etc.) y que se caracterizan por promover un periodismo independiente y abierto a la participación de la ciudadanía y los movimientos sociales. A pesar de su importante papel en el ecosistema de medios, la sostenibilidad de este tipo de proyectos ha sido escasamente abordada por una literatura académica en la que dominan las miradas celebratorias en detrimento de los estudios empíricos y comparados. El presente trabajo revisa los debates y analiza las estrategias de sostenibilidad de los medios españoles del Tercer Sector mediante la construcción y aplicación de un modelo multidimensional de indicadores que contempla tanto la financiación como otras dimensiones clave para asegurar la autonomía y misión social de estos proyectos: organizativas, ecosociales, político-legales e infotecnológicas. La metodología parte de una revisión documental de la literatura de referencia y del estudio de caso de dos experiencias paradigmáticas, una cooperativa (El Salto) y una asociación (OMC Radio), que ayudan a testar los indicadores y que son representativas de ciertas tendencias mediáticas en un contexto de crisis económica y reconversión digital.

Palabras clave: Medios comunitarios; Tercer sector de la comunicación; Comunicación participativa; Comunicación para el cambio social; Sostenibilidad; Cooperación; Voluntariado.

Claves Econlit: J54; P13; L82; D80; Q01.

[en] The sustainability of the Spanish Third Sector of Communication. Design and application of an analytic model to the case study of El Salto and OMC Radio Abstract. The Third Media Sector comprises alternative media and communication projects managed by associations,
cooperatives and non-profit organizations and characterized by the promotion of independent journalism open to the
participation of citizenship and social movements. Despite its important role in the media ecosystem, sustainability has
been scarcely addressed by an academic literature dominated by celebratory approaches at the expense of empirical and
compared studies. This article reviews the debates and analyzes the sustainability strategies of the Spanish Third Media
Sector through the construction and application of a multidimensional indicator model that combines funding with other
key dimensions to ensure the autonomy and social function of these projects: organizational, ecosocial, legal-
institutional and info-technological. Methodology is based on a review of referential academic literature and two case
studies, a cooperative (El Salto) and an NGO (OMC radio), that help test the indicators and which are representative of
certain media trends within a context of economic crisis and digital transition.

Keywords: Community media; Third communication sector; Participatory communication; Communication for social change; Sustainability; Cooperation; Volunteering.

Sumario. 1. Introducción al Tercer Sector de la Comunicación. 2. Metodologías. 3. La sostenibilidad del Tercer Sector de la Comunicación. 4. Elementos para un modelo de análisis de la sostenibilidad del TSC. 5. Aplicación del modelo a los estudios de caso. 6. Conclusiones. 7. Referencias bibliográficas.

Cómo citar. Barranquero Carretero, A.; Candón-Mena, J. (2021) La sostenibilidad del Tercer Sector de la Comunicación en España. Diseño y aplicación de un modelo de análisis al estudio de caso de El Salto y OMC Radio. REVESCO. Revista de Estudios Cooperativos, vol. 137, e71863. https://dx.doi.org/10.5209/reve.71863.

1 El artículo se adscribe a las líneas de investigación habituales de la Red de Investigación en Comunicación Comunitaria, Alternativa y Participativa (RICCAP) (www.riccap.org), en la cual se integran los investigadores.

2 Universidad Carlos III de Madrid, España.

Dirección de correo electrónico: abarranq@hum.uc3m.es.

3 Universidad de Sevilla, España.

Dirección de correo electrónico: jcandon@us.es. 


\section{Introducción al Tercer Sector de la Comunicación}

Desde el período de la Transición a la democracia, los medios comunitarios, educativos y sin ánimo de lucro han abanderado un modelo alternativo de vital importancia para el derecho a la comunicación de la ciudadanía y de los sectores ausentes o injustamente representados en los medios convencionales (Aguaded y Martín Pena, 2013; Pérez Martínez, 2017). No obstante, el Tercer Sector de la Comunicación (en adelante TSC) ha tenido que enfrentarse a numerosos obstáculos de tipo económico y regulatorio que han impedido el ejercicio efectivo de sus funciones y la existencia de un ámbito mediático diferenciado de los medios públicos y comerciales (García García, 2015). En las primeras décadas del siglo XXI se ha reactivado la investigación sobre el sector, si bien la atención a ciertas problemáticas -como el debate conceptual o el marco legal- ha ido en detrimento de un mayor interés por cuestiones clave como la sostenibilidad de este tipo de proyectos.

Algunos debates en torno al TSC se han orientado a caracterizarlo, enfatizando en su dimensión alternativa (Atton, 2015), radical (Downing, 2001), educativa (Aguaded y Martín Pena, 2013) o ciudadana (Rodríguez, 2001). Otros análisis han abordado los procesos contrahegemónicos que el sector implementa (Downing, 2001), su valor educativo (Lucas, 2014), o su potencial para catalizar la creatividad local y comunitaria (Downing, 2001; Rodríguez, 2001). Recientemente, la denominación Tercer Sector de la Comunicación se ha popularizado en España (Barranquero, 2015; Ceballos-Castro, 2019; García García, 2017; Fleischman, Reguero y Sáez, 2009) como una etiqueta inclusiva que permite enmarcar distintos tipos de proyectos caracterizados por: (1) Su carácter privado sin ánimo de lucro porque su propiedad y gestión pertenecen a una asociación, cooperativa u ONG; (2) Estar abiertos a la participación directa de la ciudadanía en los distintos aspectos de la vida del medio: desde el diseño de los contenidos a la búsqueda de financiación; (3) No realizar proselitismo religioso ni político, por lo que se excluye de la categorización a medios de partidos políticos o confesiones religiosas; (4) Estar orientados a promover la democracia, los derechos humanos y otros ideales de justicia social y medioambiental.

El TSC se define, sobre todo, por fomentar valores de servicio público muchas veces descuidados por medios públicos y privados (Brevini, 2014). Dentro de estos, la participación constituye su principal razón de ser (Carpentier, 2011), si entendemos que en los medios convencionales dicha participación se limita a un mero feedback puntual, instrumental y de ajuste de cara a mejorar el impacto en las audiencias (Beltrán, 2007). En esta línea, el ámbito se ha caracterizado por facilitar canales de expresión a colectivos que sufren discriminación o vulnerabilidad por distintas razones: personas migrantes y refugiadas (Council of Europe, 2018), mujeres (Tornay, 2017; Pérez Martínez, 2020), población reclusa (Contreras-Pulido, Martín-Pena y Aguaded, 2015), o personas sin hogar (Resende, Pardo y Nielsen, 2017). Otros estudios han destacado su importancia en la resolución de conflictos (Pérez Martínez, 2020; Rodríguez, 2015), su potencial terapéutico en el campo de la discapacidad y la salud mental (García y Meda, 2012), o su papel en la protección y promoción de lenguas y culturas minorizadas (Lema-Blanco y Meda, 2016).

Otra porción importante de la literatura ha evaluado los condicionantes históricos y las regulaciones que favorecen o limitan el desarrollo de estos medios (Fleischman, Reguero y Sáez, 2009; García García, 2015; Segura et al., 2019). No obstante, en los últimos años, el TSC ha comenzado a obtener el reconocimiento de importantes organismos supranacionales como las Naciones Unidas (2010), el Council of Europe (2009, 2018) o el Parlamento Europeo (2008). Más allá de que la falta de una identidad común obstaculiza la regulación de un ámbito -el Tercer Sector- en extremo diverso (Enjoras, Salamon, Sivesind y Zimmer, 2018), los avances en las políticas han acompañado al crecimiento de unos medios que están mejor regulados y más desarrollados en los países del Norte de Europa que en las regiones del Este, Centro o Mediterráneo (CMFE, 2012; Doliwa y Rankovic, 2014; EPRA, 2013; KEA, 2007). En América Latina, el TSC acumula una extensa experiencia de comunicación alternativa y alfabetizadora en un contexto de debilidad o ausencia de medios públicos y dominio absoluto de los medios privados (Pulleiro, 2011). En países como EE.UU., Canadá o Australia, donde su gestión oscila entre lo público y lo comunitario, estos proyectos han contribuido a la integración de comunidades nativas, latinas o afrodescendientes, y han fomentado canales de expresión juvenil y experimentación cultural (Hamilton y Atton, 2001).

En España los medios no lucrativos desempeñaron una importante función social desde el período de Transición a la democracia (Pérez Martínez, 2017; García García, 2015) evolucionando desde concepciones más militantes a modelos más inclusivos (García García, 2017). En los últimos años, la investigación mediática comparada (Hepp y Couldry, 2009) a nivel estatal ha permitido distinguir hasta cinco tipos-ideales de medios del TSC: (1) Medios comunitarios, o iniciativas a cargo de organizaciones no lucrativas y abiertas a la participación ciudadana y a diferentes vías de financiación y organización (AMARC, 2009; Parlamento Europeo, 2008). En España, la principal federación que los agrupa es la Red de Medios Comunitarios (ReMC), además de otras redes locales o regionales como la Unión de Radios Libres y Comunitarias de Madrid (URCM), Arrosa Sarea en Euskadi o la Xarxa de Ràdios Comunitàries de Barcelona (XRCB). (2) Medios libres que, frente a los comunitarios y conforme al Manifiesto de Villaverde de 1983, enfatizan en el funcionamiento autogestionario y horizontal y rechazan la publicidad y las ayudas públicas a fin de mantener 
su independencia (Pérez Martínez, 2017). (3) Medios cooperativos basados en modelos de economía social y solidaria que son propiedad de personas asociadas trabajadoras o usuarias. Estos proyectos se rigen por criterios asamblearios y se dotan de mecanismos éticos para mantener su soberanía y atender a las necesidades ciudadanas. Algunos han comenzado a organizarse en torno al Foro de Comunicación de la Economía Social y Solidaria (ESS), enmarcado en la Red de Economía Social y Solidaria (REAS) (Barranquero Carretero y Sánchez Moncada, 2018; Arévalo, Al Najjar y Vilar, 2020). (4) Medios educativos de tipo diverso, que se mueven entre modelos de gestión pública y comunitaria. Además de funciones representativas de institutos o universidades, estos proyectos suelen facilitar la participación de la comunidad académica y el entorno cercano con fines de educación, extensión y divulgación científica (Aguaded y Martín-Pena, 2013). Los medios universitarios se integran desde 2011 en la Asociación de Radios Universitarias (ARU) y aún no han sido objeto de regulación. (5) Por último, existen otras muchas organizaciones y prácticas de carácter mixto que no se definen exactamente por ser medios sino que son más bien proyectos comunicacionales populares y alternativos con distintas áreas de incidencia -jóvenes, mayores, mujeres, migrantes, etc.- y caracterizados por el empleo de distintos formatos: colectivos de video y cine participativo y comunitario (Montero y Moreno, 2020), medios nativos digitales alternativos (Tejedor y Pla Pablos, 2020), proyectos de información y activismo digital (Calvo, 2020), etc.

A pesar de ser una constante en la discusión de muchas organizaciones, la sostenibilidad ha sido una de las dimensiones más olvidadas en la investigación del TSC. De hecho, los estudios pioneros y más citados siguen siendo manuales prácticos encargados por organizaciones internacionales como la UNESCO, la Asociación Mundial de Radios Comunitarias (AMARC) o la Asociación Latinoamericana de Educación Radiofónica (ALER) (Escobar, Salgado y Dávila, 2008; Binder, Fischer y Godinez, 2017; Escobar, Salgado y Dávila, 2008; Fairbairn, 2009; Fraser y Restrepo, 2001; Pavarala et al., 2014). En un momento de institucionalización del campo académico, este artículo hace balance de los estudios de la sostenibilidad del TSC y avanza en el diseño de un modelo de indicadores compuestos para su evaluación. El modelo se aplica y contrasta en dos experiencias paradigmáticas españolas para valorar su viabilidad y ofrecer pistas para que otros medios reflexionen sobre sus modelos organizativos, sus usos tecnológicos, o su relación con las comunidades locales. La definición de indicadores se ha pensado fundamentalmente para proyectos de ámbito periodístico: radio, prensa, televisión o cibermedios. No obstante, hay otras muchas experiencias como agencias de información o de publicidad social, productoras audiovisuales, plataformas online de producción libre de conocimiento, etc.- que podrían encuadrarse en el TSC pero que no son objeto estricto de la reflexión de este artículo.

\section{Metodologías}

El objetivo de este trabajo es avanzar en un modelo de análisis de la sostenibilidad para el TSC proporcionando un conjunto de indicadores medibles que serán aplicados y contrastados a partir de un análisis piloto de dos estudios de caso. En esta línea, evitamos las miradas celebratorias y románticas (Jankowski, 2003), o el acercamiento descriptivo, normativo o militante (Ferron y Guevara, 2017) para intentar avanzar hacia una medición más rigurosa y precisa de la sostenibilidad. Nuestra propuesta de indicadores se aleja asimismo de las herramientas en exceso vagas, imprecisas e inestables desarrolladas hasta la fecha, como señala Haye (2016), o de una comprensión de la sostenibilidad identificada exclusivamente con factores de tipo económico o ambiental, del que son buen ejemplo los indicadores de medición del desarrollo sostenible (sintetizados en Singh et al., 2009).

En primer lugar, el diseño del modelo se asienta en una revisión documental de bibliografía de referencia (research review) (Randolph, 2009) en el contexto iberoamericano y anglosajón con el objeto de identificar los principales debates y distinguir las principales variables para medir la sostenibilidad del TSC. Durante la fase de descubrimiento y selección de la literatura se realizaron búsquedas en inglés y español en las bases de datos Dialnet, Scopus, ISI Web of Science (WoS) y Teseo y en Google Books, en torno a un conjunto de palabras clave -medios comunitarios, ciudadanos, alternativos, populares, participativos, libres, cooperativos, educativos, universitarios, TSC, etc.- que se combinaron con las propias del objeto: sostenibilidad, sustentabilidad, competitividad, financiación, recursos, políticas y organización. Ya en la fase hermenéutica, se atendió a tres dimensiones para la interpretación del material encontrado (Hart, 2008): (1) origen y bases teóricas de las discusiones; (2) principales tópicos y variables analizadas a propósito de la sostenibilidad; (3) y referentes intelectuales en cada debate. Dadas las peculiaridades de un objeto de estudio que se mueve entre la teoría y la práctica (Rodríguez, 2001), no solo se seleccionaron trabajos científicos sino también manuales, sistematizaciones de experiencias y literatura profesional.

En segundo lugar, el modelo se construyó a partir de una aproximación macro y micro fruto de la experiencia y el trabajo de campo de los autores. Por un lado, partimos de los fundamentos de la investigación mediática comparada (Hepp y Couldry, 2009) con el objeto de revisar las continuidades existentes entre los medios y debates del TSC en distintos contextos y entendiendo que cada contexto 
determina saberes y prácticas situadas y no siempre equiparables (Downing, 2001; Sáez-Baeza, 2009). Por otro, el modelo surgió de una revisión documental de bibliografía de referencia en torno a la medición o interpretación de la sostenibilidad del TSC, pero, posteriormente, los indicadores se aplicaron para evaluar una muestra intencional de iniciativas paradigmáticas del contexto español desde la metodología del estudio de caso (case study), lo que permitió una interpretación contextual de cada experiencia (Yin, 2003) y ayudó a poner en práctica los indicadores a modo de prueba y validación.

Los casos - una cooperativa de medios (El Salto) y una emisora comunitaria (Onda Merlín Comunitaria$O M C$ )- no constituyen muestras representativas del universo analizado, sino más bien orientativas de ciertas tendencias del sector (Flyvbjerg, 2006). Dichas experiencias fueron seleccionadas porque ilustran estrategias exitosas de sostenibilidad si consideramos los siguientes criterios: (1) ambas tienen amplia continuidad en el tiempo; (2) se han dotado de personal contratado para la gestión y la búsqueda de financiación, por lo que no dependen en exclusiva del voluntariado; (3) diversifican sus vías de financiación, organización, y relación con sus audiencias. (4) Y, por último, ambas experiencias transformaron su modelo de gestión en un proceso de reflexión motivado tras la crisis económica de 2008 y en el marco de la reconversión digital. Más allá de las continuidades, los medios se diferencian en: (1) sus formatos -prensa y multimedia (El Salto) y radio con proyectos de dinamización sociocultural $(O M C)$-; (2) y, sobre todo, en sus modelos organizativos y financieros: una cooperativa financiada mediante suscripciones y publicidad (El Salto) y una asociación no lucrativa asentada en fondos públicos y, en menor medida, fondos privados y cuotas de socios (OMC).

Para la recopilación, contraste y validación de los datos, se realizaron seis entrevistas estructuradas a personas socias y asalariadas con distintas responsabilidades de gestión y hasta alcanzar cierto nivel de saturación (Maxwell, 2005). Asimismo, hubo que reformar el cuestionario inicial y realizar más de una entrevista a cada informante con el objeto de conseguir información significativa sobre todas las variables diseñadas y a fin de establecer comparaciones entre las experiencias. La Tabla 1 resume el perfil de los informantes y de la documentación consultada: actas de asambleas, balances económicos y planes estratégicos.

Tabla. 1. Relación de fuentes consultadas

\begin{tabular}{|l|l|l|}
\hline & El Salto & OMC \\
\hline $\begin{array}{l}\text { Informantes } \\
\text { clave }\end{array}$ & $\begin{array}{l}\text { Pablo Elorduy. Consejo de } \\
\text { redacción } \\
\text { Mai Gredilla. Responsable de } \\
\text { Promoción; hasta finales de 2018 } \\
\text { responsable de contabilidad }\end{array}$ & $\begin{array}{l}\text { José Manuel Mínguez. Secretario y } \\
\text { fundador }\end{array}$ \\
José Ramón Planelles. \\
Vicepresidente y fundador \\
$\begin{array}{l}\text { Alfonso Torres. Representante de } \\
\text { El Salto Andalucía en la Junta } \\
\text { Estatal }\end{array}$ & Rebeca Escudero. Tesorera \\
\hline Documentación & $\begin{array}{l}\text { Actas II asamblea general El Salto } \\
\text { 2018 (El Salto, 2018) } \\
\text { Informe de cuentas de 2017 (El } \\
\text { Salto, 2018b) } \\
\text { Balance social entidades 2017- } \\
\text { 2018 Mercado social de Madrid } \\
\text { (MSM, 2019) }\end{array}$ & $\begin{array}{l}\text { Malance y cuentas de Resultados } \\
\text { Diciembre 2018 (OMC, 2018) }\end{array}$ \\
\hline
\end{tabular}

Fuente: Elaboración propia.

\section{La sostenibilidad del Tercer Sector de la Comunicación}

A grandes rasgos, la sostenibilidad del TSC puede ser definida como todos aquellos procedimientos que favorecen la continuidad, competitividad y fortalecimiento de los medios ciudadanos con el objetivo de preservar su carácter autosuficiente y autónomo, su misión social y su compromiso con la ciudadanía y las comunidades del entorno (Fischer, 2019: 83; Pulleiro, 2011: 138). Los estudios sobre esta dimensión suelen coincidir en tres premisas de partida. En primer lugar, resulta imposible definir un modelo único para analizarla o medirla porque la sustentabilidad depende de la posición que cada medio tiene en relación con su 
contexto y con otros actores sociales o mediáticos (Traversaro y Villagra, 2019: 4). En segundo lugar, la sostenibilidad del TSC es siempre multidimensional y dinámica (Fisher, 2019); es decir, no solo procede de factores económicos, sino de una combinación de dimensiones de tipo interno -por ejemplo, los modelos de gestión y organización del medio- y externo: el marco regulatorio y político, la relación con las comunidades, las interacciones con otras entidades sociales, mediáticas, etc. (Escobar, Salgado y Dávila, 2008; Gumucio, 2005; Haye, 2016; Kaplún, 2019). Por último, cualquier decisión en torno a la sostenibilidad tiene que favorecer la "rentabilidad social" del proyecto (Chaparro, Olmedo y Gabilondo, 2016), su orientación hacia la "diversidad cultural" (Albornoz y García Leiva, 2017), y el compromiso ético de construir sociedades más inclusivas, solidarias y fraternas (Haye, 2016: 161). Es por estas premisas que la literatura se pregunta con frecuencia por los modelos económicos que mejor garantizan su independencia organizativa y estratégica (Calvo, 2020), o por cómo estos medios se pueden articular en red de cara a intercambiar saberes, dificultades y retos (Ramos, Morais y Barranquero, 2018).

En América Latina, uno de los modelos más citados es el de Gumucio (2005), que distingue entre sostenibilidad social (relacionada con el respaldo y la participación de comunidades y sociedad civil), institucional (que atañe a políticas públicas y relaciones humanas y laborales al interior del medio) y económica (los recursos financieros). También son populares los estudios encargados por AMARC y ALER a Escobar, Salgado y Dávila (2008), Geerts, Van-Oeyen y Villamayor (2004) y Villamayor y Lamas (1998), que apuntan a diferenciar entre factores o variables más o menos similares a las diseñadas por Gumucio (2005). En tiempos recientes, dichas tipologías se han replicado o reformulado en países como Chile (CNTV, 2012; Sáez Baeza, 2008), Uruguay (Kaplún, 2019) y Argentina (Binder, Fisher y Godínez, 2017; Fisher, 2019; Iglesias, 2015, 2016; Segura, 2017; Segura et al., 2019; Traversaro y Villagra, 2019), donde los trabajos citados comienzan a componer un cuerpo incipiente de investigaciones en torno a la sostenibilidad.

En el ámbito anglosajón, las aproximaciones multidimensionales son menos frecuentes, si bien hay análisis especializados en patrones económicos (Gordon, 2009, 2015), sociales (Anderson y Rodríguez, 2019) u organizativos (King y Rahemtullah, 2019). Por su parte, la UNESCO ha celebrado encuentros y ha publicado estudios sobre la sostenibilidad de los medios comunitarios (UNESCO, 2015, 2017), además de desarrollar indicadores de desarrollo mediático (media development indicators) (UNESCO, 2008; Schneider, Hollifield, Lublinski, 2016) que también fueron revisados para la construcción del modelo.

En el ámbito de la sostenibilidad económica, la literatura reivindica la necesidad de diversificar las vías de financiación (Fairbairn, 2009; Gordon, 2009; Iglesias, 2015) y garantizar la independencia y el servicio público, lo que implica la búsqueda de fórmulas distintas a las que predominan en medios públicos y comerciales (Chaparro, Olmedo y Gabilondo, 2016). Por su parte, Milan (2009) sugiere evitar la publicidad de grandes corporaciones y empresas social y ecológicamente irresponsables. También recela de la financiación pública a gran escala (Milan, 2009).

En relación con la sostenibilidad social, uno de los principales obstáculos de estos medios radica en la ausencia o debilidad de un reconocimiento apropiado de su ámbito de influencia (Iglesias, 2016: 179). También se apunta a la necesidad de construir una relación estable y cercana con las comunidades y las entidades del entorno (Pavarala et al., 2014; Jallov, 2012). En el plano organizativo, los estudios valoran cómo afecta el tipo de personalidad jurídica (si es que la tienen); los modelos de organización, dirección y distribución de las tareas; y la profesionalización y la cantidad de voluntariado y de trabajadores estables (Traversaro y Villagra, 2019). Otros recuentos han destacado la excesiva volatilidad del voluntariado del TSC, lo que provoca dificultades para captar fondos o para mantener una continuidad en la previsión de contenidos y programas (Barranquero, 2015).

En el plano político-legal, los trabajos coinciden en lo importante de garantizar un marco regulatorio favorable (Iglesias, 2015), si bien desde la década de 2000 se ha avanzado en el reconocimiento del sector (Lewis, 2015) desde la premisa de que la regulación y el apoyo público son indicadores clave para avanzar en la democratización, la diversidad cultural o el pluralismo informativo (UN, OSCE, OEA y CADHP, 2007; UNESCO, 2008). En Europa, los progresos se han destinado a garantizar que radios y televisiones comunitarias dispongan de un espacio propio en el espectro (Parlamento Europeo, 2008; Council of Europe, 2009) y hay países como Francia, Reino Unido o Irlanda que incluso ofrecen fondos públicos permanentes para protegerlas y promocionarlas (EPRA, 2013). En Latinoamérica, normativas como la Ley 26-522 de Servicios de Comunicación Audiovisual de Argentina de 2009 (Boletín Oficial, No 31.756, 10 de octubre) asignan una reserva de un tercio del espectro radioeléctrico a medios comunitarios y educativos a fin de garantizarles una presencia equitativa junto a públicos y comerciales (Segura et al., 2019; Traversaro y Villagra, 2019). Y ya en España, la Ley 7/2010 General de la Comunicación Audiovisual, aprobada en 2010 (BOE 79 de 1 de marzo) reconoció por primera vez los denominados "servicios de comunicación comunitarios sin ánimo de lucro" pero no llegó a regular a los medios educativos. Diez años después de su aprobación, y aunque desde 2020 se está tramitando una nueva ley, dicha normativa estatal no ha sido implementada en la mayoría de las Comunidades Autónomas. Además, persisten las barreras de acceso a las licencias (Lema-Blanco y Meda, 2016), y se imponen límites a sus gastos de explotación y el pago de cánones por derechos de autor, que muchos medios son incapaces de asumir (García García, 2015). 
Por último, hay investigaciones que invitan a explorar una última dimensión de la sostenibilidad que no siempre es mencionada en la literatura. Nos referimos al potencial de interconexión y trabajo en red que facilitan tecnologías emergentes como las redes infotecnológicas o el software libre (Calvo, 2020), entendiendo que estas abren nuevas posibilidades para el trabajo colaborativo, la captación de fondos o el reclutamiento de nuevos participantes (Ramos, Morais y Barranquero, 2018). El componente tecnológico ha comenzado a incorporarse en estos medios como un factor transversal dado su potencial de moldeabilidad (Manovich, 2005), convergencia (Díaz-Noci, 2010) y remediación (Bolter y Grusin, 2000). Y aunque la sostenibilidad del TSC en el entorno digital se enfrenta a retos similares al que afrontan el resto de medios (Picard, 2011; Campos-Freire, 2015; Reig, 2015), los medios ciudadanos se diferencian por emplear tecnologías de bajo coste como un recurso logístico para actores pobres en recursos (Della-Porta y Mosca, 2005). Por último, hay estudios que destacan que Internet ha supuesto un refuerzo del capital informacional (Hamelink, 2000; Marí-Sáez y Sierra, 2008) y del capital social y de voluntariado del que dependen las organizaciones no lucrativas (Putnam, 2002). Por su parte, autores como Tilly (2005) enfatizan en el valor añadido que supone el cambio del paradigma comunicativo desde patrones centralizados hacia modelos más horizontales, participativos y propios de los movimientos sociales y del tercer sector.

En el ámbito de los medios no lucrativos europeos, el proyecto COMEPEC (2015) analizó la sostenibilidad del TSC en once países, concluyendo que los modelos de financiación oscilan entre países que enfatizan en el apoyo público y los que se sustentan en la iniciativa privada de fundaciones y organizaciones filantrópicas. Asimismo, indicó que la mejor vía para su supervivencia es la diversificación de fondos, el pluralismo interno de las organizaciones, y el apoyo de sus comunidades locales. En España, los avances sobre esta materia son muy escasos, si bien el informe "Juventud española y los medios del Tercer Sector de la Comunicación" demostró que existe una gran diversidad de fórmulas económicas, entre las que destacan los fondos públicos en forma de subvenciones directas o cesión de instalaciones (27\%), la organización de actividades lúdicas como conciertos y festivales (25\%), o las cuotas de socios, simpatizantes y programas (20\%). Solo un $15 \%$ de los medios, la mayoría comunitarios, recurría a la publicidad de comercios locales y pymes, y un 6\% a la de organizaciones sin ánimo de lucro. Otras vías de financiación eran las suscripciones y el merchandising (13\%) y las campañas de crowdfunding (6\%). Además, un 5\% de los medios declaraba sostenerse sin financiación alguna, principalmente los denominados medios libres (Barranquero, 2015).

En las conclusiones, este trabajo destacó como déficit la ausencia de un marco jurídico que proteja y asegure la sostenibilidad política y económica. Por su parte, la mayoría del casi un centenar de proyectos encuestados declaró no contar con personas contratadas y depender en exceso del trabajo voluntario, considerado una fuente de dinamismo a la vez que de inestabilidad (Barranquero, 2015). Por su parte, la Red de Medios Comunitarios (ReMC, 2018) ha realizado encuestas entre sus medios concluyendo que la mayoría maneja un presupuesto medio anual inferior a los 5.000 euros $(57 \%)$, mientras que el $10 \%$ se sitúa entre esta cifra y 10.000; el 15\% hasta 30.000; y un 25\% más de 30.000. Finalmente, son escasos los estudios sobre sostenibilidad de medios educativos o de las organizaciones de carácter mixto antes señaladas, aunque la literatura pone de relieve que las radios universitarias se apoyan en su mayoría en fondos propios de universidades públicas y privadas (Aguaded y Martín Pena, 2013; Barranquero y Navarro Limón, 2018).

\section{Elementos para un modelo de análisis de la sostenibilidad del TSC}

A partir de la literatura revisada, entendemos la sostenibilidad como un proceso multidimensional y dinámico que se relaciona, al menos, con cinco dimensiones y que debe pensarse desde los estándares internacionales en materia de diversidad cultural y derecho a la comunicación (Council of Europe, 2009; Parlamento Europeo, 2008; UNESCO, 2015, 2017). A continuación, describimos estas dimensiones y sus principales variables, que se resumen en la Tabla 3 al final del epígrafe:

- Sostenibilidad económica: Son escasas las experiencias comunitarias que sobreviven y se consolidan sin apoyo de ninguna entidad externa (Gumucio, 2005) o con el recurso exclusivo de fondos públicos o cuotas de personas asociadas o simpatizantes (Gordon, 2015). La sostenibilidad del TSC también pasa por diversificar recursos tan variados como: (1) fondos propios: cuotas de programas o de asociación al medio, cursos de formación, organización de eventos, etc.; (2) publicidad, en especial, publicidad pública, social y de organizaciones y empresas social y ecológicamente responsables; (3) ayudas y convocatorias públicas o privadas que no comprometan la independencia del medio; (4) y colaboraciones, patrocinios o partidas de fundaciones públicas, privadas y del tercer sector (Lewis, 2008; Milan, 2009; Gordon, 2015). Otra vía por explorar son los nuevos modelos derivados del ámbito digital, como el crowdfunding (Fernández Sande y Gallego, 2015; Roig, Sánchez-Navarro y Leibovitz, 2017) o los nuevos canales multiplex que combinan múltiples emisiones en una sola frecuencia y que ya desarrollan en la radio de algunos países europeos (Jauert et al., 2017). Los proyectos más sostenibles son aquellos que no dependen de una única vía de 
financiación, por lo que resulta necesario dotarse de personal especializado en la gestión y captación de fondos. Evitando el acceso restringido a contenidos y programas (pay-wall) al que tiende el entorno digital (Gordon, 2015), la función de servicio público de estos medios es recompensada en algunos países mediante fondos permanentes, que pueden derivar de recursos públicos, donaciones privadas, o impuestos a la publicidad o a los operadores comerciales. Las fórmulas de financiación también deben estar reguladas para evitar la excesiva dependencia editorial con respecto a algunas fuentes, y siempre que la normativa permita al proyecto la libertad de aceptar o no un monto más o menos limitado de publicidad (Milan, 2009: 607), tal y como hoy se observa en experiencias como La Marea o El Salto, cuya financiación se decide en asamblea para asegurar la independencia del medio (Barranquero y Sánchez Moncada, 2018). En Argentina, estudios recientes han demostrado que las políticas de fomento del sector inciden de modo directo en la mejora de infraestructuras y equipamientos, al tiempo que aumentan el número de medios y la producción propia. No obstante, se recomienda que existan autoridades independientes y especializadas en la aplicación de estas políticas, por cuanto las particularidades y diversidad de este tipo de medios dificultan de manera notable la regulación (Segura et al., 2019: 171).

- Sostenibilidad político-legal: Los medios no lucrativos dependen de un contexto externo de tipo político y legal que potencia o debilita su acción social (AMARC, 2009; Segura, 2015). Esta dimensión abarca la extensa diversidad de políticas públicas y regulaciones que, en el caso español (Meda, 2015), han resultado insuficientes de cara a promocionar esta parcela de medios. Esto contrasta con marcos regulatorios más favorables y que han resultado cruciales para el crecimiento y sustentabilidad del sector como el que prevaleció en Argentina en el período 2008-2015 (Segura et al, 2019). Las políticas no siempre facilitan el régimen de propiedad o la adquisición de licencias (Lewis, 2015) y aún son escasos los fondos públicos destinados a fortalecer el TSC como un ámbito específico y no lucrativo de medios (Gordon, 2015). El análisis de esta dimensión se ha centrado tradicionalmente en las licencias y régimen de frecuencias de los medios audiovisuales. Asimismo, los marcos políticos y jurídicos también pueden contribuir a promocionar la alfabetización y la educación digital, el derecho de acceso, o distintas vías de colaboración entre el sector público, privado y comunitario (Álvarez-Peralta, 2017). Por último, la publicidad institucional es una importante vía de financiación para los medios privados que apenas ha sido explorada en el ámbito comunitario o cooperativo. Esta podría ser incorporada siempre que no comprometa la independencia del medio y se establezcan por ley criterios claros de inversión que no dependan en exclusiva de las decisiones gubernamentales (Martínez-Pastor, 2012).

- Sostenibilidad organizativa: Dicha dimensión tiene que ver con la evaluación de las formas jurídicas, la organización y profesionalización del trabajo, la toma de decisiones, o la participación del personal al interior de un medio (Lamas y Tordini, 2007; Traversaro y Villagra, 2019). Por una parte, hablamos de evaluar los modelos de gestión para conocer si estos responden a jerarquías y dinámicas más o menos centralizadas y cómo éstas inciden en una adecuada distribución de las responsabilidades o en la identificación y participación de individuos, colectivos y organizaciones sociales (Pavarala et al., 2014). Por otra parte, es necesario conocer cómo se gestionan los recursos humanos para evaluar: el componente de personal voluntario y asalariado, sus condiciones de asociacionismo y laborales, y las motivaciones y causas de deserción del voluntariado: cansancio, conflictos internos, incumplimiento de expectativas, etc. (Barranquero, 2015). Además, conviene estudiar el grado de pluralismo interno en relación con ejes como el género, la diversidad étnico-lingüística, las ideologías políticas o la propia composición etaria. La diversidad puede fortalecer dinámicas colaborativas entre personas distintas, así como contenidos más plurales y equilibrados, entendiendo que el pluralismo interno se relaciona con el externo (Humanes et al., 2013, p. 568). Asimismo, medios y organizaciones se fortalecen cuando existe transparencia en la propiedad y en los presupuestos (por ejemplo, mediante la publicación de sus cuentas online) (Arévalo, Al Najjar y Vilar, 2020), así como cuando se promocionan programas de formación y dinamización social que, además de capacitar y empoderar, pueden ayudar a incorporar nuevos miembros y personas jóvenes (Lema-Blanco, 2015).

- Sostenibilidad ecosocial: La dimensión social es valorada como una de las más importantes para la sustentabilidad del TSC. Esta implica fortalecer, al menos, dos tipos de relaciones externas: (1) de colaboración con otras organizaciones locales, de desarrollo y de derechos humanos, y con otros medios, redes y colectivos comunicacionales; (2) y de retroalimentación con los interlocutores y las comunidades culturales, lingüísticas o de interés a las que el medio apela y que participan en la vida del proyecto. A diferencia de medios públicos y privados, los ciudadanos manejan concepciones muy difusas de sus públicos reales o potenciales y son escasos los que analizan las características de sus audiencias y recepciones. Pero 
estos estudios no deben atender a las premisas de rentabilidad del sector privado, sino enfocarse más bien al "esclarecimiento de los sentidos" que estos medios configuran en su interacción con los públicos (Osses y Valderrama, 2018: 269, 271), para el que pueden ser útiles los grupos focales o las herramientas digitales. La labor de un medio comunitario debe evaluarse no solo en sus productos sino, sobre todo, en los procesos que activa (Segura, 2015). Y la dimensión social no pude desligarse de una necesaria visión ecológica que dé cuenta del impacto y las relaciones con el entorno natural. Descuidada en la literatura del TSC, la sostenibilidad ambiental es una línea en la que trabajan ya algunos medios cooperativos, que conciben la economía como un medio -y no como un fin- al servicio del desarrollo personal, comunitario y ambiental (Boyle, 2012). Esto último implica analizar la existencia o no de: contenidos y campañas ambientales, prácticas ecológicas responsables, valoración de la huella ecológica, etc.

- Sostenibilidad infotecnológica: Esta variable es una dimensión inexcusable de cara a acometer funciones clave para la sostenibilidad y utilidad social del TSC: el establecimiento de vínculos de pertenencia; las interacciones con otros proyectos y organizaciones sociales; la incorporación de innovaciones tecnológicas para facilitar la participación o la producción de contenidos; etc. Webs, apps y redes tecnológicas pueden contribuir a proyectar las iniciativas locales en marcos más amplios; compartir contenidos y recursos técnicos, legales o económicos; intercambiar saberes y experiencias; e incluso captar nuevo voluntariado y simpatizantes (Ramos, Morais y Barranquero, 2018). La sostenibilidad tecnológica también apela a los aprendizajes obtenidos del movimiento de software libre y open source (Correia, Vieira y Aparicio, 2019; Calvo, 2020; Calvo y Campos, 2019; Iglesias, 2016) o la gestión y empleo de big data (Milan y Gutiérrez, 2015). Para todo esto es necesario que el medio esté abierto a la innovación tecnológica, la formación en TIC, y la incorporación, por ejemplo, de convenios de prácticas que estén en consonancia con sus ideales no lucrativos (Correia, Vieira y Aparicio, 2019). Por último, disponer de planes o estrategias de comunicación interna es un factor de sostenibilidad que facilita la diversidad y las afinidades entre los miembros y que puede agilizar la coordinación del trabajo, mientras que los planes de comunicación externa contribuyen a la generación de redes con otros proyectos y organizaciones.

Tabla. 2. Dimensiones y variables de análisis de la sostenibilidad en el TSC

\begin{tabular}{|l|l|}
\hline Dimensión & Variables \\
\hline $\begin{array}{l}\text { Sostenibilidad } \\
\text { económica }\end{array}$ & $\begin{array}{l}\text { Procedencia y diversificación de las fuentes; personal destinado a la } \\
\text { búsqueda y gestión de fondos; toma de decisiones sobre la financiación; } \\
\text { otros (acceso al crédito, nuevas vías como crowdfunding, fondos } \\
\text { públicos directos, etc.) }\end{array}$ \\
\hline $\begin{array}{l}\text { Sostenibilidad } \\
\text { político-legal }\end{array}$ & $\begin{array}{l}\text { Forma jurídica (cooperativas, asociaciones, fundaciones, etc.); contexto } \\
\text { político, leyes y regulaciones que afectan al medio (concesión de } \\
\text { licencias; dotación de infraestructuras; etc.); otros (promoción de la } \\
\text { educación mediática; derecho de acceso; publicidad institucional; etc.) }\end{array}$ \\
\hline $\begin{array}{l}\text { Sostenibilidad } \\
\text { organizativa }\end{array}$ & $\begin{array}{l}\text { Formas y canales de organización y coordinación del trabajo; } \\
\text { participación en la toma de decisiones; medidas para el fomento de la } \\
\text { motivación, la participación y la pertenencia al grupo; medidas de } \\
\text { transparencia, de igualdad de género, de inclusión y participación, } \\
\text { derechos laborales, etc. }\end{array}$ \\
\hline $\begin{array}{l}\text { Sostenibilidad } \\
\text { ecosocial }\end{array}$ & $\begin{array}{l}\text { Comunidad de apoyo y evaluación de logros sociales; conocimiento del } \\
\text { público (análisis de procesos y estudios de recepción); colaboración } \\
\text { de/con organizaciones locales, de derechos humanos y otros medios } \\
\text { (generalmente del TSC) y redes; valoración del impacto ambiental y de } \\
\text { las medidas destinadas a la sostenibilidad ecológica }\end{array}$ \\
\hline $\begin{array}{l}\text { Sostenibilidad } \\
\text { infotecnológica }\end{array}$ & $\begin{array}{l}\text { Uso de herramientas digitales para el establecimiento de redes o el } \\
\text { fomento de la participación; incorporación de innovaciones } \\
\text { tecnológicas; uso de software libre; acciones formativas sobre } \\
\text { comunicación y tecnologías; planes y protocolos de comunicación } \\
\text { interna y externa }\end{array}$ \\
\hline
\end{tabular}

Fuente: Elaboración propia. 


\section{Aplicación del modelo a los estudios de caso}

\subsection{El Salto}

A pesar de su relativa novedad, El Salto es uno de los proyectos más conocidos, consolidados y de mayor envergadura del TSC en España, puesto que en la actualidad se compone de más de 60 blogs y unos 20 medios de comunicación locales. A su vez, El Salto constituye un proyecto multimedia que incluye radio, vídeo y prensa en papel y digital, ocho ediciones territoriales y una plantilla fija de 20 empleados con un total de 18,5 jornadas laborales.

En relación con la sostenibilidad económica, El Salto basa su financiación, sobre todo, en suscripciones de socios. Con la base de los 5000 suscriptores alcanzados por el periódico matriz Diagonal tras 12 años de experiencia, en 2016 El Salto inicia una campaña de accionariado popular con la que consigue 2.800 nuevos socios en sus primeros meses y, ya en 2017, un monto del 64,6\% de ingresos por suscripciones. Desde entonces, el proyecto ha diversificado las modalidades de suscripción individual con distintos precios y servicios (socio digital por 3 euros al mes; en papel por 6; y socio "incondicional" por 10), así como la posibilidad de suscripción para colectivos por unos 300 euros mensuales que, junto a los servicios anteriores, incluye publicidad gratuita y el derecho a formar parte del denominado Consejo de Movimientos Sociales. Más allá de las suscripciones, el medio se refuerza al diversificar sus fuentes a través de: (1) las ventas del periódico, revistas y otros productos de merchandising (9\%); (2) la publicidad y los bonos de apoyo, igualados con el 7,6\%; (3) los servicios editoriales (5,1\%); (4) y las promociones de libros o fiestas $(2,4 \%)$ (El Salto, 2018b).

Respecto a la publicidad, esta se restringe tanto cuantitativamente, al no permitir que los ingresos publicitarios superen el $20 \%$ de los totales, como cualitativamente, a través de un código ético que limita los tipos de anunciantes y formatos publicitarios. Estos límites no impiden que el medio sea capaz de lograr una parte complementaria de sus ingresos por esta vía gracias a su amplia difusión y a una segmentación como uno de los medios de referencia de la economía social y solidaria. No obstante, el 7,6\% de ingresos publicitarios de 2017 aún están lejos del 20\% marcado como límite. Para reforzarlos, El Salto ha realizado una fuerte inversión para ser auditado por la Oficina de justificación de la difusión (OJD) y para poder acceder a una cuota mayor de publicidad institucional (Gredilla, 26/7/2019) (El Salto, 2018), una partida que suele ser bastante infrecuente o inexiste en los medios comunitarios.

Además, el proyecto se fortalece con la venta de servicios de comunicación, distribución o editoriales para otros colectivos (5,1\% de ingresos en 2017) (El Salto, 2018), lo que supone un ingreso "pequeño pero creciente" (Gredilla, 26/7/2019). También se exploran nuevas fórmulas como el aprovechamiento de la base de suscriptores para la venta de libros y se ha llegado a acuerdos con editoriales y librerías para el reparto al $50 \%$ del precio de venta y de cara a ofrecer descuentos a los suscriptores/as. La formación es otra de las vías de ingreso, para la cual se está trabajando de cara a formalizar acuerdos con universidades y centros educativos. Respecto a la financiación pública, se ha explorado el acceso a fondos europeos a través de la Red Intercontinental de Promoción de la Economía Social y Solidaria (RIPESS), hasta ahora sin éxito debido a "grandes condicionamientos en cuanto a contenidos y a la dificultad de coordinarse para tramitarlas" (Gredilla, 26/7/2019). En cuanto al personal específicamente dedicado a la captación de fondos, El Salto cuenta con una persona dedicada a la comercialización de la publicidad, otra a promocionar el medio para captar suscriptores, y una tercera que conjuga las labores comerciales con las de diseño y edición de la agencia de comunicación Edita (Gredilla, 26/7/2019). En ocasiones también se contrata a personal dedicado a la búsqueda de financiación para reforzar los nodos locales (Torres, 27/7/2019) y cabe destacar el acceso a crédito a través de Coop57.

Respecto a la dimensión político-legal, la forma jurídica de cooperativa conlleva ventajas fiscales respecto a las sociedades, pero los responsables perciben inconvenientes respecto a su tramitación burocrática y a la relación con la administración, debido a "procesos muy difíciles y lentos, el requerimiento de documentos firmados ante notario y un desconocimiento de la propia administración del modus operandi de las cooperativas" (Gredilla, 26/7/2019). En nodos locales sin personal contratado se opta por la fórmula asociación (Torres, 27/7/2019) y en el plano jurídico se reclama la existencia de una ley que regule de forma transparente el reparto de la publicidad institucional (Gredilla, 26/7/2019; Torres, 27/7/2019).

En relación con la dimensión organizativa, la coordinación del trabajo se realiza presencialmente y a través de herramientas de videoconferencia y mensajería instantánea como Telegram, y con el correo electrónico como vía más formal. Más allá de las tareas cotidianas para el fomento de la participación, la asamblea plenaria "es lo que más motiva al grupo y a sentirnos parte del proyecto" (Gredilla, 26/7/2019). Este sentimiento de pertenencia se fomenta, además, reservando espacios y tiempos de ocio y convivencia, que "es cuando más grupo se hace". Por otra parte, las reuniones presenciales se retransmiten en streaming para facilitar la participación de personas que no pueden desplazarse a Madrid (Gredilla, 26/7/2019) o se rota el punto de encuentro con objeto de facilitar la asistencia en lugares como Andalucía (Torres, 27/7/2019). 
La centralidad de Madrid es señalada como un límite a la participación difícil de solventar, tanto por la trayectoria de un proyecto que hereda una masa de suscriptores de Diagonal muy localizada en la capital como por las dificultades para deslocalizar los puestos de trabajo, por lo que, para ser contratado, "a veces es un requisito estar en Madrid" (Gredilla, 26/7/2019). Esta implantación territorial trata de equilibrarse con el apoyo a ediciones locales ( $250 €$ al mes para contenidos) o permitiendo que estas gestionen el $100 \%$ de la publicidad por ellas generada. Estos esfuerzos son bien percibidos por los nodos locales, que destacan cómo en las asambleas "la gente no vota en clave territorial y es frecuente que gente de Madrid vote defendiendo posiciones descentralizadoras" o la "amplia autonomía" respecto al uso de recursos, por lo que lo definen como "un problema bien resuelto" (Torres, 27/7/2019). En cuanto a la participación de los lectores y suscriptores del medio, esta "resulta difícil de articular, no por convicción política sino por falta de recursos", lo que hasta ahora ha impedido impulsar el foro de socias disponible en la web (Torres, 27/7/2019). No obstante, los socios/as pueden presentar y votar iniciativas a través del foro, que son posteriormente tratadas en la asamblea general (El Salto, 2018).

No se realiza un esfuerzo formalizado para la captación de voluntarios/as ya que el proyecto aspira a la profesionalización. Sin embargo, esta sigue siendo una contribución fundamental sobre todo en los nodos locales. En otro orden de cosas, el medio rechaza aceptar becarios a los que no pueda pagar. Sin embargo, sí que se reconocen, previa solicitud, las prácticas de aquellas personas que ya venían colaborando en el medio y que requieren certificarlas formalmente (Gredilla, 26/7/2019). Finalmente, el proyecto adopta medidas de transparencia al publicar sus cuentas anuales (El Salto, 2018b) o las actas de la asamblea general (El Salto, 2018). También informa a través del blog de la redacción y los boletines a las personas asociadas, y rinde cuentas en el marco del Mercado Social de Madrid con su Balance Social como entidad adscrita (MSM, 2019). Por último, se llevan a cabo medidas de igualdad como la publicación de informes sobre porcentajes de mujeres socias o trabajadoras, o la aprobación de cuotas de cara a alcanzar la paridad (El Salto, 2018; MSM, 2019).

La dimensión ecosocial resulta fundamental para la sostenibilidad de un proyecto que, pese a su diversificación, depende sobre todo de una amplia comunidad de apoyo: "un proyecto comunicativo transformador depende de una comunidad para garantizar su estabilidad, independencia y crecimiento" (López-Fernández, 2018: 91). Su comunidad está fuertemente ligada a los movimientos sociales críticos e incluso ha acompañado a distintas movilizaciones a lo largo de su historia: primero como Molotov (19862003), una publicación ligada al movimiento okupa, antimilitarista y ecologista; luego como Diagonal (2005-2016) en el marco de los movimientos de la vivienda o la cultura libre; y finalmente, a partir de 2016, al contexto del 15M, que inicia "la reflexión interna en Diagonal que da lugar al proceso de refundación en El Salto" (López-Fernández, 2018: 93). En este proceso de acompañamiento, el medio apuesta por una apertura cada vez mayor, transitando desde el enfoque contrainformativo de sus inicios al de un medio con vocación transversal y contenidos alternativos. Esto implica trascender los círculos de la izquierda militante y apostar por la profesionalización, que, según Rosique-Cedillo (2018), garantiza su sostenibilidad financiera y supone una alternativa al modelo de las grandes corporaciones.

Asimismo, el proyecto comienza a estar arraigado en algunas localidades y Comunidades Autónomas en su apuesta por crear "ediciones locales, y no solo contenidos locales, pues es lo que da cercanía con la gente y nos hace un producto atractivo" (Torres, 27/7/2019). Las entrevistas también han puesto de manifiesto el propio valor de arraigo en el territorio tanto de su producto informativo, puesto que la información local se considera "un valor que puede ser monetizable", como de un periodismo practicado "como bien social" en el que se promueven contenidos publicados en distintas lenguas y concebidos desde los distintos territorios. De hecho, la descentralización periodística es un instrumento vital para luchar contra las "desigualdades y tensiones territoriales" (Torres, 27/7/2019).

En relación con la sostenibilidad infotecnológica, El Salto tiene una fuerte vinculación con las redes de economía social como la citada RIPESS, la Red de economía alternativa y solidaria (RIPES) estatal o el Mercado social de Madrid. Aunque no pertenece formalmente a ninguna red de medios, sus responsables manifiestan tener un amplio contacto con otros medios comunitarios, educativos y ciudadanos (Gredilla, 26/7/2019).

La sostenibilidad ambiental está presente en El Salto al adoptarse medidas como ajustar la tirada para no desperdiciar papel y se está revisando el plastificado de los envíos postales para sustituirlo por un material biodegradable (Gredilla, 26/7/2019). Además el suministro eléctrico está contratado con la cooperativa de producción y consumo de energías renovables Som energía y más del 60\% del reparto de periódicos a las personas suscritas se realiza en bicicleta (Gredilla, 26/7/2019) (El Salto, 2018). Asimismo, abundan los contenidos ambientales tanto en la edición general como en blogs específicos y son varias las organizaciones ecologistas que participan en su Consejo de movimientos sociales.

Respecto a la dimensión tecnológica, en las entrevistas se habló de los límites de nuevas fórmulas como el crowdfunding, ya que "no permite una planificación estable para financiar el día a día, sino que está ligado a proyectos muy concretos o como recurso para momentos de agobio ante la amenaza de cierre" (Elorduy, 7/6/2019). Por otro lado, se puso de manifiesto la dificultad de monetizar los contenidos web (Gredilla, 
26/7/2019; Elorduy, 7/6/2019), lo que provoca que El Salto apueste por ir "más allá del servicio" e incidir en "factores emocionales o el sentimiento de pertenencia" (Elorduy, 7/6/2019). En este sentido, 2011 se señaló como una fecha clave en la que se percibe la necesidad de renovar el proyecto previo (Diagonal) y que coincide tanto con la "ola del 15M" como con la "mayor explosión de tecnologías como el 4G, móviles de nueva generación, cámaras, vídeos o el periodismo ciudadano" (Elorduy, 7/6/2019). Más allá del carácter multimedia del proyecto, que incluye prensa en papel y digital, podcast de radio y vídeo y streaming ocasional, se apuesta por aumentar la variedad y calidad del contenido multimedia, por ejemplo experimentando con infografías interactivas (Gredilla, 26/7/2019).

Por último, aunque el medio apuesta por el uso de software libre, por ejemplo contratando los servicios de alojamiento con la cooperativa Nodo50, los responsables encuentran algunas dificultades para aplicarlo en una redacción en la que aproximadamente el $50 \%$ del software utilizado es libre y el resto privativo (Gredilla, 26/7/2019). También se considera que las redes sociales libres "no tienen el mismo impacto que Facebook" (Gredilla, 26/7/2019). No obstante, el proyecto cuenta con el apoyo de un informático contratado que realiza propuestas para el uso de herramientas libres, además de otras medidas infotecnológicas como la elaboración de planes de comunicación interna y externa, un manual de estilo y un manual de promoción (Gredilla, 26/7/2019).

\subsection{OMC radio}

La segunda experiencia analizada es la asociación Onda Merlín Comunitaria radio (OMC), una asociación cultural sin ánimo de lucro dedicada a la comunicación y la educación. $O M C$ lleva más de 30 años trabajando en el distrito de Villaverde de Madrid y en otros barrios y municipios del entorno (Torrelodones, Pozuelo, Móstoles, Usera, etc.), desde que comenzó con sus emisiones en 1987.

En su sostenibilidad económica, $O M C$ es una de las pocas radios comunitarias españolas que maneja un presupuesto mayor de 30.000 euros anuales (ReMC, 2018), con un patrimonio neto de 158.517 euros según su balance económico de 2018. Al igual que otras muchas emisoras comunitarias españolas, sus fondos procedían inicialmente de cuotas de socios, venta de lotería y organización de actividades en fiestas locales (Mínguez, 3/6/2019). Como consecuencia de la crisis económica de 2008, sus presupuestos se vieron mermados y se perdió personal, por lo que el proyecto decidió "superar la barrera de la precariedad y apoyarse decididamente en tres estrategias de sostenibilidad: la combinación de asociacionismo y profesionalización, el emprendimiento social, y procesos formativos de distinto tipo y en alianza con diferentes organizaciones" (Planelles, 26/6/19). En la actualidad, solo un 6\% del presupuesto anual deriva de cuotas de socios o programas, dado que el grueso (94\%) procede de ingresos por actividades y servicios procedentes de entidades públicas, fundaciones privadas, ONG y cooperativas (64\%) y de subvenciones públicas de apoyo a la asociación (7\%) y a actividades diversas -salud, infancia, género, etc.- (23\%) (Mínguez, 3/6/2019, según balance económico de 2018). Sin apoyo, por el momento, de financiación publicitaria, $O M C$ ha conseguido sostenerse en base a convenios y convocatorias de ayudas de administraciones públicas (de Comunidad de Madrid, ayuntamientos de pueblos del entorno, juntas de distrito, etc.), fundaciones y todo tipo de organizaciones y cooperativas con fines sociales. Casi todas las personas asalariadas dedican parte de su jornada a la captación de fondos, sin las cuales el proyecto no sería posible en su forma actual (Planelles, 26/6/19). Por el momento, $O M C$ carece de financiación de programas europeos, si bien ya ha habido ensayos previos y su Junta directiva lo percibe como una posibilidad futura.

En relación con la sostenibilidad político-legal, $O M C$ se formaliza como asociación sin ánimo de lucro en 1988. Su forma jurídica tiene ventajas como la de optar a subvenciones e incluso licitaciones. No obstante, la forma asociación conlleva desventajas burocráticas que ralentizan el trabajo y el acceso a vías menos habituales de financiación. En el ámbito legal, el proyecto padece de los mismos problemas que el resto de emisoras comunitarias españolas, por lo que comparte las demandas de las redes de las que es socia (URCM y ReMC), en particular la reivindicación de que es necesario mejorar la Ley General de la Comunicación Audiovisual de 2010 y desarrollarla a nivel autonómico. De hecho, "resulta paradójico que la última Junta de distrito de Villaverde y todos los partidos políticos por unanimidad hayan reconocido el importante papel social jugado por la asociación" y que, sin embargo, la radio siga careciendo de licencia y espacio en el dial "para distinguirse de otras emisoras privadas y piratas" (Planelles, 26/6/19). Empero, OMC estuvo emitiendo en FM hasta que cambiaron de local en 2015 y decidieron parar sus emisiones debido al alto coste económico de instalar una nueva antena y transmisor. Desde entonces, venían emitiendo en streaming y podcasting, si bien en 2018 se decidió reactivar sus emisiones mediante la compra e instalación de equipamiento técnico.

Con ayuda de la URJC, en la actualidad existe una comisión formada por voluntariado de la entidad que está realizando el estudio técnico y acometer las tareas administrativas necesarias para volver a la FM (Escudero, 5/6/2019). En panorama adverso, $O M C$ ha apostado desde sus inicios por asociarse en red (por ejemplo, con redes internacionales como AMARC y nacionales como ReMC y URCM) y por mantener convenios activos tanto con universidades como, sobre todo, con centros educativos de primaria, secundaria 
y FP de la Comunidad de Madrid en localidades como Móstoles, Villaverde u Orcasitas, centros a los que ofrecen capacitaciones en comunicación y clases de refuerzo en Secundaria de cara a prevenir el fracaso escolar en la región (Mínguez, 3/6/2019). Esta apuesta por la educación mediática y de valores una de las principales estrategias utilizadas por OMC de cara a legitimarse frente a las instituciones, obtener recursos públicos o incorporar a nuevos miembros. También trabaja en red con distintas entidades e iniciativas del distrito retransmitiendo actividades, sonorizando eventos o promocionándolos desde la emisora (Escudero, 5/6/2019).

Ya en la dimensión organizativa, $O M C$ cuenta en la actualidad con más de una decena de personas contratadas a las que intenta dar seguridad y emplea en actividades diversas (Escudero, 5/6/2019). Sin embargo, sus promotores reconocen que resulta difícil encontrar el equilibrio entre personas asalariadas y voluntarias, o entre los intereses personales y profesionales y los estrictamente sociales, que a veces colisionan (Planelles, 26/6/19). El mecanismo para la toma de decisiones es la Junta directiva, que se elige en la asamblea abierta a personas colaboradoras, simpatizantes y socias. Son estas últimas las que, cada tres años, eligen a la Junta, que en la actualidad está compuesta por un número mayor de mujeres (5) que de hombres (3) (Planelles, 26/6/2019) y en la que conviven personas voluntarias y asalariadas (Escudero, 5/6/2019). Además, hay reuniones frecuentes entre los equipos de coordinadores de proyectos y las personas trabajadoras. Por otra parte, la asociación se guía por ideales de inclusión y transparencia como la publicación anual en su web de la Memoria de actividades (OMC, 2018) y del Balance económico (OMC, 2018b). Además, se ha dotado de Planes de Igualdad y de Voluntariado que se entregan a la persona voluntaria que accede por primera vez al proyecto (Planelles, 26/6/19).

En el ámbito de la sostenibilidad ecosocial, los esfuerzos de $O M C$ han trascendido la mera emisión de contenidos en radio para convertirse en un espacio de formación ciudadana e incidencia comunitaria. En este sentido, su actividad es extensa y variada y abarca áreas como la igualdad de género (programas como Ondas nómadas o Mayores en las ondas), la prevención de la salud y las terapias en salud mental (Villaverde saludable, Ábrete camino o Mejor imposible) o la atención a colectivos en riesgo de exclusión como personas sin hogar. También implementa numerosos programas dirigidos a estimular el empoderamiento juvenil y de las personas mayores a través de cursos de capacitación, programas de radio o campañas de prevención en salud. $O M C$ no ha realizado por el momento estudios de audiencias o recepciones, si bien todos los proyectos subvencionados y en los que participa el voluntariado se evalúan con cuestionarios (Planelles, 26/6/19). Sus responsables consideran que esta labor ha de afianzarse en el futuro con una estrategia más sólida que permita conocer las necesidades del entorno y de las organizaciones locales. Otra asignatura pendiente es la sostenibilidad ecológica, si bien en los últimos tiempos su personal ha comenzado a aplicar estrategias de reciclaje en el local, y ya en 2019 campañas como Muévete contra el plástico en alianza con las cada vez más populares Lideresas de Villaverde (Rodríguez-Pina, 2018).

En el plano de la sostenibilidad infotecnológica, $O M C$ carece de un plan de comunicación protocolizado aunque sí dispone de un manual de uso de redes sociales, que le permite divulgar e interactuar con sus comunidades en distintas redes de tipo comercial como Facebook o Twitter (Planelles, 26/6/19). Asimismo, la organización ha colaborado con URCM y ReMC en campañas de crowdfunding como las orientadas a recuperar el informativo estatal coordinado Más Voces, que emitió de 2006 a 2014. Si bien esta campaña de 2015 no alcanzó el éxito buscado y el informativo no se volvió a emitir, este rótulo forma parte del título de uno de los principales programas informativos de la emisora: Más voces Villaverde. La emisora tampoco ha apostado decididamente por fórmulas de financiación en el ámbito digital, si bien algunos de sus programas (El abrazo del oso, Sexo y lo que surja, etc.) han ensayado fórmulas de financiación y monetización a partir de descargas en plataformas como iVoox.

Inspirada en la escala exploratoria desarrollada por Haye (2016), la Tabla 4 evalúa cada medio en base a las descripciones antes expuestas y asignando una valoración cualitativa (de alta $=3$, media $=2$ y baja $=1$ ) a cada uno de los indicadores diseñados. Esta propuesta avanza en la propuesta de "indicadores compuestos" para medir la sostenibilidad del TSC, entendidos estos como herramientas de análisis de fenómenos complejos y multidimensionales -como la sustentabilidad-mediante una síntesis de múltiples indicadores individuales (Freudenberg, 2003) y abordando las diferentes dimensiones no aisladamente sino de forma interrelacionada, sistémica y combinada (Azcárate, Fernández y Carrasco, 2015; Nardo et al., 2005). Útiles para medir conceptos multidimensionales que no pueden ser captados por un solo indicador, estos instrumentos ayudan a interpretar de manera sencilla y efectiva dimensiones complejas y cuentan con enormes potencialidades para elaborar rankings, visualizaciones, mediciones o comparaciones entre distintas unidades de análisis (como los medios y proyectos del TSC) en distintos contextos temporales o geográficos (OECD y JRC, 2008). 
Tabla. 3. Comparación de los estudios de caso

\begin{tabular}{|c|c|c|}
\hline & El Salto & OMC \\
\hline \multicolumn{3}{|l|}{ Sostenibilidad económica } \\
\hline Procedencia y diversificación de las fuentes & 3 & 3 \\
\hline Personal destinado a la búsqueda y gestión de fondos & 3 & 2 \\
\hline Toma de decisiones sobre la financiación & 3 & 3 \\
\hline $\begin{array}{l}\text { Otros (acceso al crédito, nuevas vías como crowdfunding, fondos } \\
\text { públicos directos, etc.) }\end{array}$ & 2 & 2 \\
\hline \multicolumn{3}{|l|}{ Sostenibilidad político-legal } \\
\hline Forma jurídica (cooperativas, asociaciones, fundaciones, etc.) & 3 & 3 \\
\hline $\begin{array}{l}\text { Contexto político, leyes y regulaciones que afectan al medio } \\
\text { (concesión de licencias; dotación de infraestructuras; etc.) }\end{array}$ & 2 & 1 \\
\hline $\begin{array}{l}\text { Otros (promoción de la educación mediática; derecho de acceso; } \\
\text { publicidad institucional; etc.) }\end{array}$ & 2 & 2 \\
\hline \multicolumn{3}{|l|}{ Sostenibilidad organizativa } \\
\hline Formas y canales de organización y coordinación del trabajo & 3 & 3 \\
\hline Participación en la toma de decisiones & 3 & 3 \\
\hline $\begin{array}{l}\text { Medidas para el fomento de la motivación, la participación y la } \\
\text { pertenencia al grupo }\end{array}$ & 2 & 3 \\
\hline $\begin{array}{l}\text { Medidas de transparencia, de igualdad de género, de inclusión y } \\
\text { participación, derechos laborales, etc. }\end{array}$ & 3 & 3 \\
\hline \multicolumn{3}{|l|}{ Sostenibilidad ecosocial } \\
\hline Comunidad de apoyo y evaluación de logros sociales; & 3 & 3 \\
\hline $\begin{array}{l}\text { Conocimiento del público (análisis de procesos y estudios de } \\
\text { recepción); }\end{array}$ & 2 & 1 \\
\hline $\begin{array}{l}\text { Valoración del impacto ambiental y de las medidas destinadas a la } \\
\text { sostenibilidad ecológica; etc. }\end{array}$ & 2 & 1 \\
\hline \multicolumn{3}{|l|}{ Sostenibilidad infotecnológica } \\
\hline $\begin{array}{l}\text { Uso de herramientas digitales para el establecimiento de redes o el } \\
\text { fomento de la participación }\end{array}$ & 3 & 2 \\
\hline Incorporación de innovaciones tecnológicas & 2 & 1 \\
\hline Uso de software libre & 2 & 1 \\
\hline Acciones formativas sobre comunicación y tecnologías & 1 & 1 \\
\hline Planes y protocolos de comunicación interna y externa & 2 & 1 \\
\hline
\end{tabular}

Fuente: Elaboración propia.

\section{Conclusiones}

El presente artículo ha reflexionado acerca de las estrategias de sostenibilidad que afronta el Tercer Sector de la Comunicación en España en el marco de la crisis económica, la reconversión digital y el reciente ciclo de movilizaciones sociales (de 2011 en adelante), factores a los que los informantes asignan más o menos peso en la sostenibilidad y evolución de los proyectos. Respectivamente, la revisión documental y los estudios de caso han servido para diseñar y testar un modelo multidimensional de indicadores compuestos que analiza la sustentabilidad no solo desde un plano económico sino también desde otras dimensiones que aseguran la autonomía y misión social de estos proyectos: el marco político y legal; la fortaleza interna de las organizaciones (dimensión organizativa); la creación de sinergias y redes entre medios, ciudadanía o medioambiente (ecosocial); o el impulso de planes y estrategias de comunicación derivadas o no del entorno digital (infotecnológica). 
El modelo operativiza estas cinco dimensiones abordándolas de forma separada, si bien las cinco están interconectadas y pueden tener distinto peso según el contexto y el tipo de medio. Por ejemplo, la sostenibilidad infotecnológica contribuye a la mejora de la organizativa y viceversa y, a su vez, ambas son interdependientes de políticas públicas de apoyo o fomento económico del sector. Tras el análisis, también nos planteamos si se deben establecer escalas de medición diferentes en relación con el tipo de medio. Por ejemplo, la dimensión político-legal parece resultar más determinante en medios audiovisuales comunitarios que dependen de licencias para emitir como $O M C$, mientras que la infotecnológica es una variable central para medios nativos digitales o que dan mucha importancia a su edición digital (El Salto), puesto que necesitan de la red para ampliar su base comunitaria y de suscriptores/as. Por su parte, la dimensión organizacional es vital para medios cooperativos en los que los niveles de profesionalización suelen ser más acentuados que en los medios comunitarios (Barranquero Carretero y Sánchez Moncada, 2018). No obstante, estos últimos tienden a dotarse cada vez más de personal específicamente destinado a las tareas de búsqueda y gestión de fondos (García García, 2017). Más allá de la orientación comparativa de nuestro estudio, estas consideraciones nos llevan a advertir que el modelo propuesto no debe ser concebido como una propuesta única o universalizante sino que sus componentes deben ser pensados y readaptados en función de los distintos contextos mediáticos, sociopolíticos o culturales.

De la revisión de literatura y testimonios se desprende que la diversificación de fuentes de ingresos, la previsión de personal orientado a la búsqueda de fondos y la existencia de una amplia comunidad de apoyo, son tres de los factores más determinantes de cara a garantizar la supervivencia a largo plazo de un proyecto. No obstante, los medios analizados -como otros muchos otros proyectos del TSC- aún presentan importantes carencias en el conocimiento del público al que van dirigidos y, sobre todo, en relación con las escasas medidas de sostenibilidad ecológica. A estos déficits, se suma el aún exiguo aprovechamiento del potencial infotecnológico que podrían ofrecer el software libre o la formación avanzada en TIC, que consideramos factores clave de cara a reforzar el capital informacional y social del que dependen cooperativas, asociaciones y organizaciones sin ánimo de lucro.

El modelo fue testado mediante el análisis piloto de dos estudios de caso consolidados que representan cierta tendencia del TSC a diversificar sus modelos de organización y financiación para asegurar su supervivencia en tiempos de crisis y escasez de recursos. No obstante, sería interesante que posteriores investigaciones contribuyesen a repensar y validar el modelo aplicándolo, por ejemplo, a proyectos de distinta envergadura y tamaño o que manejen distintas visiones y culturas organizacionales, más allá de compartir señas de identidad como la participación o los modelos asamblearios. En cualquier caso, la utilidad de este modelo se basa en su capacidad para sugerir dimensiones y líneas estratégicas que podrían ser readaptadas en función del contexto, o que podrían servir para identificar y reforzar factores desatendidos en la literatura. En este sentido, una tarea pendiente para próximos estudios sería la de aplicar la propuesta a una muestra más amplia de medios, o la de combinar indicadores cualitativos como los aquí diseñados con otros cuantitativos que no se exploraron (ej. número de trabajadores/as y voluntarios/as; ingreso percibido por cada fuente de financiación, etc.). Estas líneas ayudarían a seguir validando las variables propuestas e incluso a generar datos estadísticos sociales (INE, 1991) que pueden ser útiles para el diseño de políticas públicas. En el campo de la comunicación en España, ya hay intentos sólidos que avanzan en esta dirección como los indicadores de "rentabilidad social" del audiovisual municipal y comunitario (Chaparro, Olmedo y Gabilondo, 2016) o los indicadores de "diversidad cultural" aplicados a la industria mediática (Albornoz y García Leiva, 2017; Marengui, 2019), o a cada uno de los tres compontes o principios de que se compone dicha diversidad (Napoli, 1999): la exposición, las fuentes (Cañedo, 2019a) o los contenidos (Cañedo, 2019b).

\section{Referencias bibliográficas}

Aguaded, I. y Martín-Pena, D. (2013) Educomunicación y radios universitarias: panorama internacional y perspectivas futuras. Chasqui. Revista Latinoamericana de Comunicación, $\mathrm{N}^{\circ}$ 124, pp. 63-70. https://revistachasqui.org/index.php/chasqui/article/view/20/30.

Albornoz, L.A. y García Leiva, T. (2017) Diversidad audiovisual, industria cultural y gobernanza. En L.A. Albornoz y T. García Leiva (eds.), Diversidad e industria audiovisual. El desafío cultural del siglo XXI (pp. 23-59). México: Fondo de Cultura Económica.

Álvarez-Peralta, M. (2017) Demandas de reforma mediática y momento populista. La circulación de las propuestas de democratización de los medios en el espacio político post-partidista. IC Revista de Información y Comunicación, $\mathrm{N}^{\circ}$ 14, pp. 121-157. https://idus.us.es/xmlui/handle/11441/68896.

AMARC (2009) Principios para un marco regulatorio democrático sobre radio y TV comunitaria. Montevideo: Asociación Mundial de Radios Comunitarias (AMARC). www.vivalaradio.org/medioscomunicacion/PDFs/MED derecho 04principios.pdf. 
Anderson, H. y Rodríguez, C. (2019) Is community radio in crisis in the Global North? Lessons from Australia and the United States. Journal of Alternative and Community Media, Vol. 4, $\mathrm{N}^{\mathrm{o}}$ 4, pp. 65-81. https://researchrepository.griffith.edu.au/bitstream/handle/10072/397839/Anderson443954-Published.pdf?sequence=2.

Atton, C. (ed.) (2015) The Routledge Companion to Alternative and Community Media. Oxon: Routledge.

Arévalo, A.I., Al Najjar, T. y Vilar, G. (2020) Medios informativos alternativos y economía solidaria en España. Psicoperspectivas, Vol. 19, № 2, pp. 1-13.

https://www.psicoperspectivas.cl/index.php/psicoperspectivas/article/view/1939.

Azcárate, F., Fernandez, M., y Carrasco, F. (2015) Sustainability Reporting and Integrated Indicators: Exploratory Analysis of Defining Characteristics. A Critical Reflection. Innovar. Revista de ciencias administrativas y sociales, Vol. 25, N 56, pp. 83-98. DOI: http://dx.doi.org/10.15446/innovar.v25n56.48992.

Barranquero, A. (coord.) (2015) Juventud española y los medios del Tercer Sector de la Comunicación. Madrid: Centro Reina Sofía sobre Adolescencia y Juventud y FAD. https://jovenesytercersector.files.wordpress.com/2016/01/juventud tercer_sector_comunicacion.pdf.

Barranquero Carretero, A. y Sánchez Moncada, M. (2018) Cooperativas de medios en España. Un periodismo emprendedor y ciudadano en tiempos de crisis. REVESCO. Revista de Estudios Cooperativos, Segundo Cuatrimestre, No 128, pp. 36-58. DOI: https://doi.org/10.5209/REVE.60735.

Barranquero, A. y Navarro Limón, M. (2018) La participación de los sectores juveniles en los medios comunitarios y educativos del Estado español. Una perspectiva comparada. En D. Martín-Pena y A. Vivas Moreno (eds. y coords.), Radios universitarias en marcha: hacia la construcción de una contra agenda mediática (pp. 66-85). Avellaneda: Undav Ediciones. http://bibliotecadigital.cin.edu.ar/handle/123456789/2298.

Beltrán, L.R. (2007) Un adiós a Aristóteles: La comunicación "horizontal". Punto Cero, № 12, pp. 69-92. http://www.scielo.org.bo/scielo.php?script=sci_arttext\&pid=S1815-02762007000200009.

Binder, I., Fisher, P. y Godínez, F. (2017) Como sea. Sostenibilidad económica-administrativa en radios comunitarias de Argentina. Buenos Aires: Jinete Insomne. https://cpr.org.ar/comosea/.

Bolter, J. y Grusin, R. (2000) Remediation: Understanding New Media. Cambridge, MS: MIT Press.

Boyle, D. (2012) Good News. A co-operative solution to the media crisis. Manchester: Co-operatives UK. https://www.uk.coop/resources/good-news-co-operative-solution-media-crisis.

Brevini, B. (2014) Public service and community media. En R. Mansell y P.H. Ang (eds.), The International Encyclopedia of Digital Communication and Society. London: John Wiley \& Sons. DOI: https://doi.org/10.1002/9781118767771.wbiedcs045.

Camacho, M. y Horta, R. (2020) Metodologías para la Construcción de Índices Compuestos. UCU Departamento de Administración y Finanzas Working Papers.

https://ucu.edu.uy/sites/default/files/facultad/fce/daf_wp_1-2020_camacho_horta_indicadores_compuestos.pdf.

Calvo, D. (2020) ‘¿Quién sustenta a quienes sustentan a los comunes?’: Tecnología y cultura libre ante el capitalismo informacional. Teknokultura, Vol. 17, No 1, pp. 13-22. DOI: http://dx.doi.org/10.5209/TEKN.64581.

Calvo, D. y Campos, E. (2019) Think global, Act locally: the virtual and the physical y free culture movement in Spain. IC Revista Científica de Información y Comunicación, $\mathrm{N}^{\mathrm{o}}$ 16, pp. 357-389. http://icjournal-ojs.org/index.php/ICJournal/article/view/457.

Campos-Freire, F. (2015) Adaptación de los medios tradicionales a la innovación de los metamedios. El Profesional de la Información, Vol. 24, No4, pp. 441-450. DOI: http://dx.doi.org/10.3145/epi.2015.jul.11.

Cañedo, A. (2019a) Austerity versus Diversity: The Production of News Content in Televisión del Principado de Asturias. Communication \& Society, Vol. 32, No 4, pp. 77-92. DOI: https://doi.org/10.15581/003.32.4.77-92.

Cañedo, A. (2019b) Televisiones autonómicas y diversidad: análisis de la programación de Televisión del Principado de Asturias. CIC. Cuadernos de Información y Comunicación, $\mathrm{N}^{\mathrm{o}} \quad 23, \quad \mathrm{pp} .113-133$. https://revistas.ucm.es/index.php/CIYC/article/view/64637/4564456552066.

Carpentier, N. (2011) Media and Participation. A site of ideological-democratic struggle. Bristol: Intellect.

Ceballos-Castro, G. (2019) Tercer Sector español ante la comunicación, el desarrollo y el cambio social. Convergencia. Revista de Ciencias Sociales, Vol. 27, pp. 1-17. https://www.redalyc.org/jatsRepo/105/10562755011/html/index.html.

Chaparro, M., Olmedo, S. y Gabilondo, V. (2016) El indicador de la rentabilidad social en comunicación (IRSCOM): Medir para transformar. CIC. Cuadernos de Información y Comunicación, Vol. 21, pp. 47-62. DOI: https://doi.org/10.5209/CIYC.52944.

CMFE-Community Media Forum Europe (2012) Community Radio/Television Stations in Europe. CMFE. http://cmfe.eu/docs/CMFE_DCTV.pdf.

CNTV (2012) Televisiones comunitarias chilenas ante el desafío de la televisión digital. Consejo Nacional de Televisión.

https://www.academia.edu/9028273/Televisiones_comunitarias_chilenas_ante_el_desaf\%C3\%Ado_de_la_TV_Digi tal_2012_CNTV.

COMEPEC-Community Media, Professionnal Euro Certification (2015) Un project Européen pour avancer sur un referentiel de formation pour les radios associatives et communataires en Europe. Syndicat National des Radios Libres-SNRL. http://www.snrl.fr/Leonardo-Comepec_r51.html. 
Contreras-Pulido, P., Martín-Pena, D. y Aguaded, J.I. (2015) Derribando el autoestigma: Medios de comunicación en prisiones como aliados de la inclusión social. Cuadernos.info, Vol. 36, pp. 15-26. DOI: https://doi.org/10.7764/cdi.36.708.

Correia, R., Vieira, J. y Aparicio, M. (2019). Community radio stations sustainability model: An open-source solution. Radio Journal: International Studies in Broadcast \& Audio Media, Vol. 17, No 1, pp. 29-45. DOI: https://doi.org/10.1386/rjao.17.1.29_1.

Council of Europe (2009) Declaration of the Committee of Ministers on the role of community media in promoting social cohesion and intercultural dialogue. Strasbourg: Council of Europe. https://wcd.coe.int/ViewDoc.jsp?id=1409919.

Council of Europe (2018) Spaces of Inclusion. An explorative study on needs of refugees and migrants in the domain of media communication and on responses by community media. Strasbourg: Council of Europe. https://rm.coe.int/dgi2018-01-spaces-of-inclusion/168078c4b4.

Della-Porta, D. y Mosca, L. (2005) Global-Net for Global Movements? A Network of Networks for a Movement of Movements. Journal of Public Policy, Vol. 25, No 1, pp. 165-190. DOI: https://doi.org/10.1017/S0143814X05000255.

Díaz-Noci, J. (2010) Medios de comunicación en internet: algunas tendencias. El profesional de la información, Vol. 19, No 6, pp. 561-567. DOI: https://doi.org/10.3145/epi.2010.nov.01.

Doliwa, U. y Rankovic, L. (2014) Time for community media in Central and Eastern Europe. Central European Journal of Communication, Vol. 7, $\mathrm{N}^{\circ}$ 12, pp. 18-33. https://www.cejc.ptks.pl/Central-European-Journal-ofCommunication-Volume-7-No-1-12-Spring-2014/Time-for-community-media-in-Central-and-Eastern-Europe.

Downing, J. (2001) Radical Media: Rebellious Communication and Social Movements. Thousand Oaks, CA: Sage Publications.

Downing, J. (ed.) (2010) Encyclopedia of social movement media. Thousand Oaks, CA: Sage.

El Salto (2018) Actas II Asamblea General El Salto $2018 . \quad$ El Salto. http://saltamos.net/docs/actas2_asamblea_elsalto.pdf.

El Salto (2018b) Con ustedes... las cuentas de El Salto. El Salto, 24 de mayo. www.elsaltodiario.com/salto-decarro/con-ustedes-las-cuentas-de-el-salto-de-2017-2108.

Enjolras, B., Salamon, L.M., Sivesind, K.H. y Zimmer, A. (2018) The third sector as a renewable resource for Europe: Concepts, impacts, challenges and opportunities. Cham: Palgrave.

EPRA-European Platform of Regulatory Authorities (2013) Local and Community Media: A comparative Report. EPRA. https://cdn.epra.org/attachments/files/2313/original/WG2_LCM_report finalversion.pdf?1390387055.

Escobar, R., Salgado, V. y Dávila, E. (2008) Atrapa sueños. La sostenibilidad en las radios populares y comunitarias. Buenos Aires: ALER y AMARC-ALC. http://www.amarcmexico.org/pdf/internacional/02-AtrapaSuenos.pdf.

Fairbairn, J. (ed.) (2009) Community Media Sustainability Guide. Arcata \& Washington: USAID, Internews \& Pact. https://internews.org/sites/default/files/2017-08/InternewsCommunityMediaGuide2009.pdf.

Fernández Sande, M. y Gallego, J.I. (2015) Crowdfunding as a source of financing for radio and audio content in Spain. Quaderns del CAC, Vol. 18, No 41, pp. 43-51. https://eprints.ucm.es/34429/.

Ferron, B. y Guevara, E. (2017) Sociología política de la 'Comunicación para el Cambio Social': Pistas para un cambio de enfoque. Commons. Revista de Comunicación y Ciudadanía Digital, Vol. 6, No 1, pp. 45-62. https://revistas.uca.es/index.php/cayp/article/view/3303.

Freudenberg, M. (2003) Composite indicators of country performance: A critical assessment. OECD Science, Technology and Industry Working Papers. Paris: OECD Publishing.

Fisher, P. (2019) By any means: Paths to sustainability for Argentina's community radio stations. Journal of Alternative and Community Media, Vol. 4, No 4, pp. 80-92. DOI: https://doi.org/10.1386/joacm_00068_1.

Fleischman, L., Reguero, N. y Sáez, C. (2009) Políticas de comunicación y sustentabilidad del tercer sector de la comunicación: el caso catalán en el contexto español y europeo. En Actas del VII Congreso Internacional de ULEPICC: Políticas de cultura y comunicación: creatividad, diversidad y bienestar en la Sociedad de la Información. $\quad$ Vol. $1, \quad$ pp. $377-405 . \quad$ ULEPICC. http://www.medioscomunitarios.net/barcelona/IMG/pdf/Ulepicc09 TSC VF2.pdf.

Flyvbjerg, B. (2006) Five Misunderstandings About Case-Study Research. Qualitative inquiry, Vol. 12, № 2, pp. 219245. DOI: http://dx.doi.org/10.1177/1077800405284363.

Fraser, C. y $\quad$ Restrepo, S. (2001) Community Radio Handbook. UNESCO. https://unesdoc.unesco.org/ark:/48223/pf0000124595.

García García, J. y Meda, M. (2012) ¡Qué locura de radio! Radios comunitarias y salud mental en España (pp. 309322). En M. Martínez, C. Mayugo y A. Tamarit (eds.), Comunicación y comunidad. Prácticas comunicativas y medios comunitarios en Europa y América Latina. Madrid: Fragua.

García García, J. (2015) Obstáculos y posibilidades al despliegue de las emisoras comunitarias. En A. Nerekan, M.A. Casado, R. Zallo y J.C. Miguel de Bustos (eds.), Comunicación de proximidad: cada vez más lejos. Marco, experiencias y regulación (pp. 279-296). Leioa: Universidad del País Vasco-UPV. https://addi.ehu.es/bitstream/handle/10810/26204/USPDF152234.pdf?sequence=1\&isAllowed=y.

García García, J. (2017) Transformaciones y aprendizajes de las radios comunitarias en España: Hacia un modelo de radio inclusiva. Disertaciones, Vol. $10, \quad \mathrm{~N}^{\mathrm{o}} 1, \quad$ pp. $30-41 . \quad$ DOI: http://dx.doi.org/10.12804/revistas.urosario.edu.co/disertaciones/a.4535. 
Geerts, A., Van-Oeyen, V. y Villamayor, C. (2004) La radio popular y comunitaria frente al nuevo siglo: La práctica inspira. Quito: ALER y AMARC.

Gordon, J. (2009) Community Radio, Funding and Ethics. En J. Gordon (ed.). Notions of community: A collection of community media debates and dilemmas (pp. 59-80). Oxford: Peter Lang.

Gordon, J. (2015) The economic tensions faced by community radio. En C. Atton (ed.), The Routledge Companion to Alternative and Community Media broadcasters (pp. 247-257). Oxon: Routledge.

Gumucio, A. (2005) Arte de equilibristas: la sostenibilidad de los medios de comunicación comunitarios. Punto Cero, Vol. $10, \quad \mathrm{~N}^{\mathrm{o}} \quad 10, \quad$ pp. 6-19. http://www.scielo.org.bo/scielo.php?script=sci_arttext\&pid=S181502762005000100002\&lng=es\&nrm=iso.

Hamelink, C. (2000) The Ethics of Cyberspace. London: Sage. DOI: http://dx.doi.org/10.4135/9781446219911.

Hamilton J. y Atton, C. (2001) Theorizing Anglo-American alternative media: toward a contextual history and analysis of US and UK scholarship. Media History, Vol. 7, $\mathrm{N}^{\mathrm{o}}$ 2, pp. 119-135. DOI: https://doi.org/10.1080/13688800120092200.

Hart, C. (2008) Doing a literature review: Releasing the social science research imagination. London: Sage.

Haye, R. (2016) Medios sustentables más allá de lo económico (156-173). O. Bosetti y R. Haye (comps.), Radio, comunicación y nuevas tecnologías: Encrucijadas del nuevo milenio. Avellaneda, Buenos Aires: UNDAV y ARUNA.

Hepp, A. y Couldry, N. (2009) What should comparative media research be comparing? Towards a transcultural approach to 'media cultures'. En D. Thussu (ed.), Internationalizing media studies (pp. 32-48). Abingdon: Routledge. http://eprints.1se.ac.uk/52470/1/Couldry_Comparative_media_research_2009.pdf.

Herrera, S. (2003) La participación del público en los medios: análisis crítico e intentos de solución. Comunicación y Sociedad, Vol. 16, No 1, 57-94. http://dadun.unav.edu/handle/10171/8037.

Huesca, R. (2008) Tracing the history of participatory communication approaches to development: A critical appraisal (180-198). En J. Servaes (ed.). Communication for development and social change. London: Sage.

Humanes, M.L., Montero-Sánchez, M.D., Molina-de-Dios, R. y López-Berini, A. (2013) Pluralismo y paralelismo político en la información televisiva en España. Revista Latina de Comunicación Social, Vol. 68, pp. 566-581. DOI: 10.4185/RLCS-2013-990.

Iglesias, M.E. (2015) “A contramano”. Modelos de gestión y estrategias económicas de las radios comunitarias argentinas en búsqueda de la sustentabilidad (2005-2015). Tesis de Máster no publicada. Universidad Nacional de Quilmes. $\quad$ https://cpr.org.ar/wp-content/uploads/media/uploads/documents/investigacionpidc/martin-iglesias-acontramano-mi-cc.pdf.

Iglesias, M.E. (2016) Sustentabilidad/sostenibilidad de los medios comunitarios y universitarios: tres provocaciones para pensar nuevas realidades. O. Bosetti y R. Haye (comps.), Radio, comunicación y nuevas tecnologías: Encrucijadas del nuevo milenio (pp. 174-186). Avellaneda, Buenos Aires: UNDAV y ARUNA.

INE-Instituto Nacional de Estadística (1991) Indicadores Sociales. Madrid: INE.

Jallov, B. (2012) Empowerment radio. Voices building a community. Gudhiem, Denmark: Empowerhouse. http://www.unesco.org/new/fileadmin/MULTIMEDIA/HQ/CI/CI/pdf/empowerment_radio_birgitte_jallov.pdf.

Jankowski, N. (2003) Community media research: A quest for theoretically grounded models. Javnost-The Public, Vol. 10, No pp. 5-14. DOI: https://doi.org/10.1080/13183222.2003.11008818.

Jauert, P., Ala-Fossi, M., Föllmer, G., Lax, S. y Murphy, Kenneth (2017) The future of radio revisited: Expert perspectives and future scenarios for radio media in 2025. Journal of radio \& audio media, Vol. 24, No 1, pp. 7-27. DOI: https://doi.org/10.1080/19376529.2017.1310574.

Kaplún, G. (coord.) (2019) ¿Vivir o sobrevivir? Sostenibilidad de las alternativas mediáticas en Uruguay. Montevideo: Altermedia y Friedrich Ebert Stiftung. http://library.fes.de/pdf-files/bueros/uruguay/15739-20191204.pdf.

KEA-Kern European Affairs (2007) The state of community media in the European Union. Brussels: European Parliament. CULT_ET\%282007\%29408943.

King, G. y Rahemtullah, O. S. (2019) Community radio contradictions in Canada: Learning from volunteers impacted by commercialising policies and practices. Journal of Alternative and Community Media, Vol. 4, No 4, pp. 20-36. https://doi.org/10.1386/joacm_00064_1.

Lamas, E. y Tordini, X. (2007) El diseño colectivo de la gestión. Un proyecto, cuatro dimensiones. Buenos Aires: Colectivo La Tribu. www.vivalaradio.org/gestion-radios-comunitarias/organizacion/gestion.html.

Lema-Blanco, I. (2015) Los medios de comunicación comunitarios como espacios de educación no formal para los/las jóvenes. Revista de Estudios e Investigación en Psicología y Educación, Vol. 14, pp. 14-28. DOI: http://dx.doi.org/10.17979/reipe.2015.0.14.315.

Lema-Blanco, I. y Meda, M. (2016) Linguistic diversity and Communication rights: the role of community media in the promotion of regional or minority languages in Europe. Radio, sound \& society journal, Vol. 1, N ${ }^{\circ}$ 1, pp. 26-41. http://hdl.handle.net/2183/18410.

Lewis, P. (2008) Finding and funding Voices: The London experience. Information, Society and Justice, Vol. 2.1, pp. 520. http://repository.londonmet.ac.uk/44/1/InformationSocietyAndJustice\%20v2,n1\%20p5-20.pdf.

Lewis, P. (2015) Community media policy. En C. Atton (ed.), The Routledge Companion to Alternative and Community Media (pp. 179-188). Oxon: Routledge. 
López-Fernández, F. (2018) Potencialidades, límites, contradicciones y retos del cuarto poder en red. De Diagonal a El Salto. Commons. Revista de Comunicación y Ciudadanía Digital, Vol. 7, N$^{\mathrm{o}}$ 1, pp. 77-111. DOI: http://dx.doi.org/10.25267/COMMONS.2018.v7.i1.03.

Lucas, E. (2014) Livret Européen de compétences. Bénévolat dans les radios associatives et communautaires en Europe. Paris: Fréquence Sill. http://frequence-sille.org/cooperation/les-productions-collectives.

Manovich, L. (2005) El lenguaje de los nuevos medios de comunicación. La imagen en la era digital. Barcelona: Paidós.

Marengui, P. (2017) Aportes metodológicos para un modelo de medición de la diversidad en televisión. En L. Albornoz, M.T. y García-Leiva (eds.), Diversidad e industria audiovisual. El desafío cultural del siglo XXI (pp. 220-246). México: Fondo de Cultura Económica.

Marí-Sáez, V. y Sierra, F. (2008) Capital informacional y apropiación social de las nuevas tecnologías. Las redes críticas de empoderamiento local en la sociedad europea de la información. Telos: Cuadernos de comunicación e innovación, $\quad \mathrm{N}^{\mathrm{r}} \quad 74, \quad$ pp. https://dialnet.unirioja.es/servlet/articulo?codigo=2545831\&orden=149485\&info=link.

Martínez-Pastor, E. (2012) Publicidad Institucional de las Administraciones Públicas: marco jurídico y controversias. Comunicación y hombre, $\mathrm{N}^{\circ} 8$, pp. 51-63. https://comunicacionyhombre.com/article/publicidad-institucional-lasadministraciones-publicas-marco-juridico-controversias/.

Maxwell, J.A. (ed.) (2005) Qualitative Research Design: An Interactive Approach. Newbury Park, CA: Sage.

Meda, M. (2015) El tratamiento de los medios comunitarios en el marco de la Ley General de la Comunicación Audiovisual. Tesis Doctoral no publicada. Universidad Complutense de Madrid. https://eprints.ucm.es/33015/1/T36345.pdf.

Milan, S. (2009) Four steps to community media as a development tool. Development in Practice, Vol. 19, No 4-5, pp. 598-609. DOI: https://doi.org/10.1080/09614520902866421.

Milan, S. y Gutiérrez, M. (2015) Medios ciudadanos y big data: La emergencia del activismo de datos. Mediaciones, Vol. 11, No 14, pp. 10-26. DOI: https://doi.org/10.26620/uniminuto.mediaciones.11.14.2015.10-26.

Montero, D. y Moreno, J.M. (2020) Explorando el campo de conocimiento del video participativo. Un recorrido por las principales aportaciones teórico-prácticas. Revista Internacional de Comunicación y Desarrollo (RICD), Vol. 3, N 11, pp. 92-108. https://doi.org/10.15304/ricd.3.11.6345.

MSM-Mercado Social de Madrid (2019) Balance social entidades 2017-2018. Madrid: MSM. https://madrid.mercadosocial.net/land/wp-content/uploads/balance_social_entidades_2019_2.pdf.

Naciones Unidas (2010) Informe del Relator Especial sobre la promoción y protección del derecho a la libertad de opinión y de expresión, Frank La Rue. Naciones Unidas, 26 de marzo. https://ap.ohchr.org/documents/dpage_s.aspx? $\mathrm{m}=85$.

Napoli, P. M. (1999) Deconstructing the diversity principle. Journal of Communication, Vol. 49, № 4, pp. 7-34. DOI: https://doi.org/10.1111/j.1460-2466.1999.tb02815.x.

Nardo, M., Saisana, M., Saltelli, A. y Tarantola, S. (2005) Tools for Composite Indicators Building. European Commission, Ispra.

OECD y JRC. (2008) Handbook on constructing composite indicators: methodology and user guide. OECD publishing. https://www.oecd.org/sdd/42495745.pdf.

OMC (2018) Memoria de actividades 2018 Enero-Diciembre 2018. Madrid: OMC. https://www.omcradio.org/wpcontent/uploads/2019/02/OMC-Radio-Memoria-2018.pdf.

OMC (2018b) Balance y cuentas de Resultados 2018. Madrid: OMC. https://www.omcradio.org/wpcontent/uploads/2019/02/Balance-y-Cuentas-de-resultados_OMC_2018.pdf.

Osses, S. y Valderrama, C. (2018) Producción de sentidos en medios comunitarios. Hacia la construcción de una Red Colaborativa. Fase 1 (proyecto finalizado). Nómadas, Vol. 49, pp. 269-272. DOI: http://dx.doi.org/10.30578/nomadas.n49a16.

Pavarala, V., Malik, K.K., Belavadi, V., Deshbandhu, A. y Raghunath, P. (2014) Community Radio Continuous Improvement Toolkit, Version 2.0. UNESCO Chair on Community Media, University of Hyderabad. http://hdl.handle.net/11599/764.

Parlamento Europeo (2008) Resolución del Parlamento Europeo de 25 de septiembre de 2008, sobre los medios del tercer sector de la comunicación, 2008/2011(INI). www.europarl.europa.eu/sides/getDoc.do?pubRef=//EP//TEXT+TA+P6-TA-2008-0456+0+DOC+XML+V0//ES.

Parlamento Europeo (2010) Directiva 2010/13/UE del Parlamento Europeo y del Consejo, 10 de marzo de 2010, sobre la coordinación de determinadas disposiciones legales, reglamentarias y administrativas de los Estados miembros relativas a la prestación de servicios de comunicación audiovisual (Directiva de servicios de comunicación audiovisual). Diario oficial, n. L 95/1 de 15/4/2010. https://eur-lex.europa.eu/legalcontent/ES/ALL/?uri=celex\%3A32010L0013.

Pérez Martínez, J.E. (2017) ¿Por qué las radios libres invadieron nuestro dial? Reflexiones sobre el concepto de anomia comunicacional como origen de proyectos de comunicación alternativa (1976-1989). Estudios sobre el Mensaje Periodístico, Vol. 23, № 1, pp. 519-534. DOI: http://dx.doi.org/10.5209/ESMP.55611.

Pérez Martínez, J.E. (2020) Feminismo, ecologismo, pacifismo y democratización de las comunicaciones en un distrito del sur de Madrid: el caso de Onda Sur (Villaverde), Journal of Spanish Cultural Studies, Vol. 21, № 2, $239-254$. DOI: https://doi.org/10.1080/14636204.2020.1760436. 
Picard, R. (2011) The Economics and Financing of Media Companies. New York, NY: Fordham University Press. $2^{\text {nd }}$. Ed.

Pulleiro, A. (2011) La radio alternativa en América Latina: Debates y desplazamientos en la década de 1990. Buenos Aires: Universidad de Buenos Aires.

Putnam, R. (2002) Solo en la bolera. Colapso y resurgimiento de la comunidad norteamericana. Barcelona: Galaxia Guttenberg.

Ramos, J., Morais, S. y Barranquero, A. (2018) Las redes de comunicación alternativa y ciudadana en España.: Potencialidades, dificultades y retos. OBETS: Revista de Ciencias Sociales, 13(1), 121-148. DOI: https://doi.org/10.14198/obets2018.13.1.05.

Randolph, J. (2009) A guide to writing the dissertation literature review. Practical assessment, research \& evaluation, Vol. 14, No 13, pp. 1-13. http://pareonline.net/getvn.asp? $=14 \& \mathrm{n}=13$.

ReMC (2018) Mejora levemente el estado de salud del sector de los medios comunitarios. REMC. https://medioscomunitarios.net/2019/03/encuesta-sobre-la-salud-de-los-medios-comunitarios-2018.

Reig, R. (2015) Crisis del sistema, crisis del periodismo: contexto estructural y deseos de cambio. Barcelona: Gedisa.

Resende, V., Pardo, M.L. y Nielsen, G. (2017) Pobreza y periodismo: ¿prácticas transformadoras? Introducción. Sur le journalisme, Vol. 6, $\mathrm{N}^{\mathrm{o}}$ 1, pp. 29-37. http://www.surlejournalisme.kinghost.net/rev/index.php/slj/issue/view/14.

Rodríguez, C. (2001) Fissures in the Mediascape. An International Study of Citizen's Media. Cresskill, NJ: Hampton Press.

Rodriguez, C. (2015) Community media as performers of peace. En J. Hoffmann y V. Hawkins (eds.), Communication and peace: Mapping an emerging field (pp. 289-302). London: Routledge.

Rodríguez-Pina, G. (2018) Antes abuelas, ahora 7 lideresas. El País, 21 diciembre. https://elpais.com/ccaa/2018/12/20/madrid/1545319925_916773.html.

Roig, A., Sánchez-Navarro, J. y Leibovitz, T. (2017) Multitudes creativas. El crowdsourcing como modelo para la producción audiovisual colectiva en el ámbito cinematográfico. El Profesional de la Información, Vol. 26, $\mathrm{N}^{\circ}$ 2, pp. 238-248. DOI: https://doi.org/10.3145/epi.2017.mar.10.

Rosique-Cedillo, G. (2018) El Salto: un estudio de caso sobre las televisiones Comunitarias en España. En J. CandónMena (ed.), Actas del II Congreso Internacional Move.net sobre Movimientos Sociales y TIC (359-372). Sevilla: COMPOLÍTICAS. https://hdl.handle.net/11441/70765.

Sáez Baeza, C. (2008) Tercer sector de la comunicación: teoría y praxis de la televisión alternativa. Una mirada a los casos de España, Estados Unidos y Venezuela. Tesis Doctoral no publicada. Universidad Autónoma de Barcelona. https://ddd.uab.cat/pub/tesis/2008/tdx-1021109-003052/csb1de2.pdf.

Sáez-Baeza, C. (2009) Invisibilización de la comunicación alternativa: propuestas de entrada y salida. Revista latina de

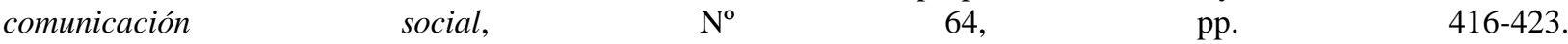
www.revistalatinacs.org/09/art/34_833_44_ULEPICC_16/Chiara_Saez.html.

Scifo, S. (2014) Communication rights as a networking reality: Community radio in Europe. En C. Padovani y A. Calabrese (eds.). Communication rights and social justice. Global transformations in media and communication research (pp. 164-179). London: Palgrave.

Schneider, L., Hollifield, A. y Lublinski, J. (2016) Measuring the business side. Indicators to Assess Media Viability, International Programme for the Development of Communication. DW Akademia for UNESCO. https://www.dw.com/downloads/36841789/dw-akademiediscussion-papermedia-viability-indicators.pdf.

Segura, M.S. (2015) Los medios comunitarios, populares y alternativos de Argentina desde la ley audiovisual. De la lucha por la legalidad al debate sobre la sostenibilidad. Diálogos de la comunicación, No 92, pp. 1-24. https://ri.conicet.gov.ar/handle/11336/78734.

Segura, M.S. y Waisbord, S. (2016) Media movements: Civil society and media policy reform in Latin America. London: Zed Books.

Segura, M. S. et al. (2017) Documento de trabajo. Sostenibilidad en las radios y televisoras comunitarias, populares y/ o alternativas. Dimensiones, categorías e indicadores. Equipo PIO CONICET/Defensoría del Público. Mimeo. https://comunicacionsfl.wordpress.com/2017/07/31/sostenibilidad-en-las-radios-y-televisoras-comunitariaspopulares-yo-alternativas-dimensiones-categorias-e-indicadores/.

Segura, M. S. et al. (2019) Las políticas públicas y la sostenibilidad de los medios comunitarios en Argentina: evaluación de resultados a diez años de una regulación innovadora. Revista Eptic, Vol. 21, No 3, pp. 155-173. https://seer.ufs.br/index.php/eptic/article/view/12480.

Singh, R. K., Murty, H. R., Gupta, S. K., \& Dikshit, A. K. (2009) An overview of sustainability assessment methodologies. Ecological Indicators, Vol. $9, \quad \mathrm{~N}^{\mathrm{o}} 2, \quad$ pp. 189-212. DOI: http://dx.doi.org/10.1016/j.ecolind.2008.05.011.

Tejedor, S y Pla Pablos, A. (2020) Análisis del modelo de ingresos en medios nativos digitales de carácter alternativo de España. Revista de Comunicación, Vol. 19, № 1, pp. 275-295. DOI: http://dx.doi.org/10.26441/rc19.1-2020-a16.

Tilly, C. (2005) Los movimientos sociales entran en el siglo XXI. Política y sociedad, Vol. 42, No 2, pp.11-35. https://revistas.ucm.es/index.php/POSO/article/view/POSO0505230011A.

Tornay, M.C. (2017) Derecho a la comunicación, género y ciudadanía: cambio social y empoderamiento de las mujeres a través de los medios comunitarios. Realidad: Revista de Ciencias Sociales y Humanidades, No 149, 171-197. DOI: https://doi.org/10.5377/realidad.v0i149.5669. 
UN, OSCE, OEA y CADHP (2007) Declaración conjunta sobre diversidad en la radiodifusion. Washington. http://www.oas.org/es/cidh/expresion/showarticle.asp?artID=719\&lID=2.

UNESCO (2008) Media development indicators: a framework for assessing media development. Paris: UNESCO y PICD. https://unesdoc.unesco.org/ark:/48223/pf0000163102.

UNESCO (2015) Community Radio Sustainability Policies and Funding. Background paper. International seminar, 1415 Septiembre, Paris: UNESCO.

http://www.unesco.org/new/fileadmin/MULTIMEDIA/HQ/CI/CI/pdf/Events/cms_sept15_background_paper_en.pdf.

UNESCO (2017) Community Media Sustainability: UNESCO's Policy Series targeting broadcasting regulators. UNESCO. https://www.epra.org/news_items/community-media-sustainability-unesco-s-policy-series-targetingbroadcasting-regulators.

Valderama, C.E. y Osses, S.L. (2019) El proceso es el modelo. Hacia el estudio de recepción de radios comunitarias. Chasqui, No 140, pp. 113-128. https://revistachasqui.org/index.php/chasqui/article/view/3862.

Villagra, E., Traversaro, N. y Segura, M.S. (2018) Medios comunitarios, audiencias y sostenibilidad. El caso de la provincia de Córdoba. RevCom, No 9, pp. 1-10. DOI: https://doi.org/10.24215/24517836e024.

Villamayor, C. y Lamas, E. (1998) Manual de gestión de la radio comunitaria y ciudadana. Quito: AMARC y Fundación Friedrich Ebert.

Yin, R. (2003) Case Study Research: Design and Methods. Beverly Hills, CA: Sage. 